\title{
SYNTHESIS OF POROUS SILICATES
}

\author{
M. M. Helmkamp and M. E. Davis \\ Chemical Engineering, California Institute of Technology, Pasadena, \\ California 91125
}

KEY WORDS: zeolite, structure-directing agent, thermodynamics, kinetics, ordered mesoporous materials

\begin{abstract}
The issues of importance and future concern in the synthesis of porous silicates and porous materials that contain a large fraction of silica, e.g. zeolites and other crystalline molecular sieves, are reviewed. The thermodynamics of zeolite synthesis are discussed, including a detailed thermodynamic analysis of the synthesis of pure-silica ZSM-5. The kinetics of porous silicate synthesis are reviewed, with particular emphasis on the control of porous structure formation through the use of organic structuredirecting agents. Ordered mesoporous materials are discussed in the context of distinguishing their features from zeolites in order to describe further the unique properties of each class of material. Finally, several unresolved issues in the understanding of the synthesis process are outlined, the resolutions of which would aid in the synthesis of porous silicates by design.
\end{abstract}

\section{INTRODUCTION}

The technological importance of silicon dioxide is enormous. Its widespread use in vastly different applications, e.g. electronic materials, catalysts and adsorbents, ranks it as one of the most critical materials for advanced societies. In this paper we discuss one form of silicon dioxide, namely, porous silicon dioxide. We describe the issues of importance and future concern in the synthesis of porous silicas and porous materials that contain a large fraction of silica, e.g. zeolites and other crystalline 
molecular sieves. We concentrate on the synthesis of crystalline materials; however, other porous silicates are also discussed, e.g. ordered mesoporous silica, when it is necessary to distinguish their features from zeolites in order to describe further the unique properties of each class of material.

Zeolites are crystalline aluminosilicates that were first discovered in 1756 by the mineralogist AF Cronstedt. He reported a new class of silicate minerals that when heated in a blowpipe flame behaved in a unique manner, i.e. the solid emitted large amounts of water vapor $(1,2)$. Cronstedt designated these minerals as zeolites-a combination of two Greek words meaning boiling stones. Zeolites are tectoaluminosilicates in that they are composed of $\mathrm{TO}_{4}$ tetrahedra ( $\mathrm{T}=$ tetrahedral atom, i.e. $\mathrm{Si}, \mathrm{Al}$ ); each apical oxygen atom is shared between adjacent tetrahedra. Thus the framework ratio of $\mathrm{O} / \mathrm{T}$ equals 2 for all zeolites (3).

Due to its valency, a silicon atom prefers to make bonds with four nearby oxygen atoms in a tetrahedral geometry. In solution, $\mathrm{a} \mathrm{SiO}_{4}$ group would have a formal charge of -4 because the silicon cation carries a formal charge of +4 and each oxygen anion has a formal charge of -2 . In a solid, because each oxygen atom forms a bridge between two $\mathrm{T}$ atoms and shares electron density with each, the $\mathrm{SiO}_{4}$ unit is neutral (see Figure 1). Therefore, a pure $\mathrm{SiO}_{2}$ framework without any defects will be a neutral solid (3). If an aluminum atom is tetrahedrally coordinated to oxygen atoms in a similar manner, the +3 valency of aluminum will result in a net formal charge of -1 . When silicon and aluminum are both present in a tetrahedral framework, a negative charge is affiliated with every aluminum atom; a cation $\left(\mathrm{M}^{+}\right.$in Figure 1$)$ balances the negative charge. Alkali metal ions, e.g. $\mathrm{K}^{+}, \mathrm{Na}^{+}$; alkaline earth ions, e.g. $\mathrm{Ba}^{2+}, \mathrm{Ca}^{2+}$; and protons, $\mathrm{H}^{+}$,
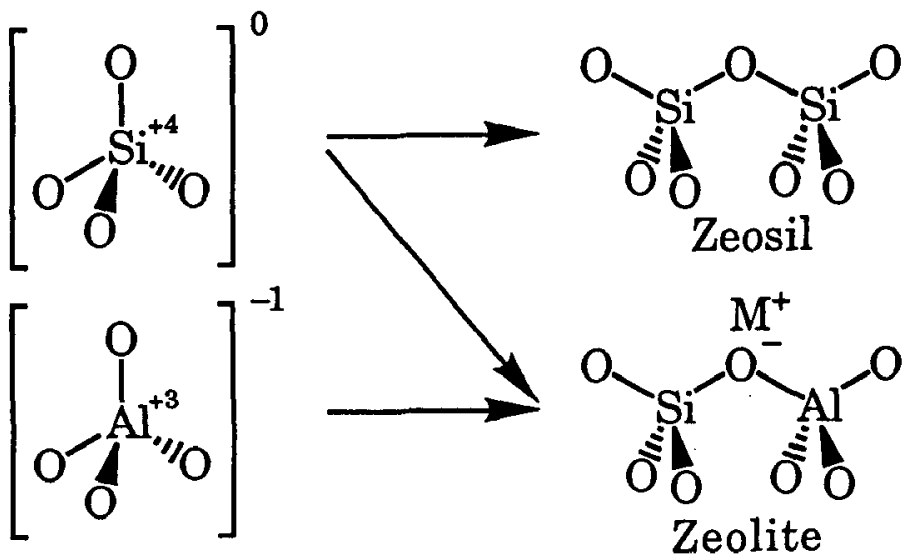

Figure $1 \quad \mathrm{TO}_{2}$ units in zeosils and zeolites. (Adapted from 3.) 
are typical balancing cations. All tectoaluminosilicates that are synthesized via hydrothermal methods (described below) have ratios of $\mathrm{Si} / \mathrm{Al} \geqslant 1$. This effect was first explained by Löewenstein (4), who assumed that isolated negative charges (- $\mathrm{Al}-\mathrm{O}-\mathrm{Si}-\mathrm{O}-\mathrm{Al}^{-}-\mathrm{O}-\mathrm{Si}$ ) are more stable than adjacent ones (- $\mathrm{Al}-\mathrm{O}-\mathrm{Al}^{-}-\mathrm{O}-\mathrm{Si}-\mathrm{O}-\mathrm{Si}$ ). This principle is now referred to as Löewenstein's rule.

The modern age of zeolite science and technology really began in the 1950s when the large scale syntheses of several zeolites were accomplished by workers at Union Carbide $(5,6)$. Since then, the use of zeolites has burgeoned both in size, e.g. over 300,000 metric tons per year for use in powdered laundry detergents as environmentally benign replacements for polyphosphates, and diversity, e.g. catalysts, adsorbents, and MRI contrast agents. As stated by Breck, "Rarely in our technological society does the discovery of a new class of inorganic materials result in such a wide scientific interest and kaleidoscopic development of applications as has happened with the zeolite molecular sieves" (7). Informative, short reviews on zeolites include those of Newsam $(8,9)$, Smith (10), Davis $(3,11)$, Gies (12), Davis \& Lobo (13), Lobo et al (14), Burkett \& Davis (15), and Higgins (16).

Strictly speaking, zeolites are aluminosilicates. In 1978, Flanigen et al (17) announced the synthesis and characterization of a pure-silica polymorph of a zeolite called ZSM-5. [In this paper we discuss numerous zeolites. If the reader is unfamiliar with a particular zeolite, details of the structure can be found elsewhere (18).] Is a pure-silica molecular sieve a zeolite? The answer is really no; however, the term zeolite is used loosely in the literature. Liebau and co-workers have proposed general classifications for materials that are four-connected tetrahedral frameworks (see Table 1) $(19,20)$. Materials with framework densities (FD), i.e. the number of tetrahedra per $\mathrm{nm}^{3}$, of less than 21 are arbitrarily denoted as porous (18). Porous frameworks can be classified depending on their pore sizes and

Table 1 Classification of tectosilicates ${ }^{\mathrm{a}}$

\begin{tabular}{|c|c|c|c|}
\hline \multicolumn{2}{|c|}{ Porosils, $\mathrm{SiO}_{2}$} & \multicolumn{2}{|c|}{$\begin{array}{c}\text { Porolites, } \mathrm{Si}_{0.5+x} \mathrm{Al}_{0.5-x} \mathrm{O}_{2} \\
(0 \leqslant x \leqslant 0.5)\end{array}$} \\
\hline Clathrasils & Zeosils & Clathralites & Zeolites \\
\hline Silica sodalite & Silica ZSM-5 & Sodalite & Faujasite \\
\hline Silica ZSM-39 & Silica ZSM-12 & Melanophlogite & Mordenite \\
\hline DD3R & SSZ-24 & & ZSM-5 \\
\hline & & & Zeolite A \\
\hline
\end{tabular}

${ }^{\mathrm{a}}$ Adapted from Reference 20 


\section{HELMKAMP \& DAVIS}

framework compositions. Materials with frameworks that allow access to the intracrystalline void spaces through rings consisting of $6 \mathrm{~T}$ atoms or 6 oxygen atoms (6-membered rings, or $6 \mathrm{MR}$ ) or smaller and that tend to trap ions or organic molecules within the intracrystalline space are denoted as clathrasils $\left(\mathrm{SiO}_{2}\right)$ or clathralites $\left(\mathrm{Si}_{0.5+x} \mathrm{Al}_{0.5-x} \mathrm{O}_{2}, 0 \leqslant x \leqslant 0.5\right)$. When the access to the crystal interior is by larger rings that permit ion exchange and/or diffusion of organic molecules, these materials are classified as zeosils $\left(\mathrm{SiO}_{2}\right)$ or zeolites $\left(\mathrm{Si}_{0.5+x} \mathrm{Al}_{0.5-x} \mathrm{O}_{2}, 0 \leqslant x \leqslant 0.5\right)$. Additionally, frameworks of composition $\mathrm{Si}_{y} \mathrm{M}_{z} \mathrm{O}_{2}, y+z=1.0$ can be formed, e.g. $\mathrm{GeO}_{2}$, $\mathrm{Si}_{0.5} \mathrm{Ge}_{0.5} \mathrm{O}_{2}, \mathrm{Si}_{0.9} \mathrm{Zn}_{0.1} \mathrm{O}_{2}, \mathrm{Si}_{0.95} \mathrm{~B}_{0.05} \mathrm{O}_{2}$. For these cases, the best way to denote these framework oxides is to call them crystalline molecular sieves.

In this discussion, we are primarily concerned with clathrasils, zeosils, zeolites, and molecular sieves of the form $\mathrm{Si}_{y} \mathrm{M}_{z} \mathrm{O}_{2}$, where $y \gg z$. Pure-silica and high-Si/M materials are somewhat hydrophobic, and this property is important to the discussion presented below. We describe the state-of-theart in the preparation of porous high-silica materials and outline several unresolved issues that would aid in the synthesis of these classes of materials by design.

\section{PREPARATION OF POROUS SILICATES}

Porous silicates are normally prepared by hydrothermal synthesis techniques. A typical crystallization procedure involves the use of water, a silica source, a mineralizing agent, and a structure-directing agent. The sources of silica are numerous and include colloidal silica, e.g. Ludox ${ }^{\mathrm{TM}}$ fumed silica, precipitated silica, and even silicon alkoxides such as $\mathrm{Si}\left(\mathrm{OCH}_{3}\right)_{4}$ and $\mathrm{Si}\left(\mathrm{OCH}_{2} \mathrm{CH}_{3}\right)_{4}$. The typical mineralizing agent is $\mathrm{OH}^{-}$but $\mathrm{F}^{-}$can also give good results. (In addition to dissolving the silica, $\mathrm{OH}^{-}$ and $\mathrm{F}^{-}$can expand the coordination sphere of silicon and produce 5 or 6 coordinate intermediates in solution). The structure-directing agent is a soluble organic species, e.g. a quaternary ammonium ion, that assists in the formation of the silica framework and ultimately resides within the intracrystalline voids (see below). Alkali metal ions such as $\mathrm{Na}^{+}$and $\mathrm{K}^{+}$ can also play a role in the crystallization process. The syntheses can be sensitive to the reagent type, the order of addition, the mixing (or lack of mixing), the crystallization temperature and time, and of course, the composition. This is riot surprising since numerous complex reactions, equilibria, and organic-inorganic interactions are occurring during the synthesis process. Additionally, if the synthesis contains a heteroatom (M), then the type and concentration can have an important role in the product formed. To set the stage for further discussions, a typical synthesis of a zeosil, e.g. pure-silica ZSM-5, would be as follows: Tetra- 
propylammonium $\left(\mathrm{TPA}^{+}\right)$hydroxide in water is combined with fumed silica at a composition of

$$
1 \mathrm{~mol} \mathrm{TPA}^{+} \mathrm{OH}^{-}: 10 \mathrm{~mol} \mathrm{SiO}_{2}: 380 \mathrm{~mol} \mathrm{H}_{2} \mathrm{O}
$$

and the mixture $(\mathrm{pH} \sim 12)$ is heated at $423 \mathrm{~K}$ in a closed reaction vessel for 3 days. Upon quenching the reaction, the pure-silica ZSM-5 crystals containing occluded $\mathrm{TPA}^{+}$are recovered by filtration from the aqueous solution. The crystals are washed with water and allowed to dry. Below, we discuss the processes that occur during this type of synthesis and the progress that is being made toward rationally designing the crystallization process in order to create new materials or known materials with framework atoms in particular crystallographic positions specified a priori (21).

\section{THERMODYNAMICS}

\section{Energetic Stability of Silicates}

Because various silicas can be used as reagents for the synthesis of porous, crystalline silicates, what is the driving force for this transformation? Additionally, why do these syntheses not yield quartz, the most stable form of $\mathrm{SiO}_{2}$ ? (According to the Ostwald ripening effect, given enough time, metastable phases will be transformed into more stable forms, until eventually the most stable phase will result.) Petrovic et al (22) recently measured the enthalpies of formation of porous, crystalline silicates and compared the values to those of quartz and amorphous silicas; the results begin to partially answer the aforementioned questions. Figure 2 shows the enthalpy of formation of silicates relative to quartz as a function of molar volume $\left(\mathrm{cm}^{3} / \mathrm{mol} \mathrm{SiO}\right)$. Note that all of the porous silicates are energetically metastable with respect to quartz and silica glass by at most 14 and $6 \mathrm{~kJ} / \mathrm{mol}$, respectively. It is known that amorphous silicas derived from gels are energetically less stable than silica glass by $0-10 \mathrm{~kJ} / \mathrm{mol}(23$, 24). Therefore, zeosils and amorphous silicas have very similar energies. At $373 \mathrm{~K}$ (close to the lower limit for synthesis), the thermal energy (RT) is $3.1 \mathrm{~kJ} / \mathrm{mol}$, so the transformation of amorphous silica into zeosils is not energetically hindered (25).

Navrotsky et al (25) measured the enthalpies of formation for ordered mesoporous and zeolitic silicas as a function of pore diameter (see Figure 3 ). [It should be noted that while zeolites are microporous crystalline materials, mesoporous silicas are amorphous (see below) (26).] Although the energy changes significantly within the small pore region below 1.0 $\mathrm{nm}$, above a pore size of $1.0 \mathrm{~nm}$, the enthalpy relative to quartz reaches a plateau of approximately $15 \mathrm{~kJ} / \mathrm{mol}$. These data illustrate a transition from a domain in which the pores or cages appear to play an integral role 


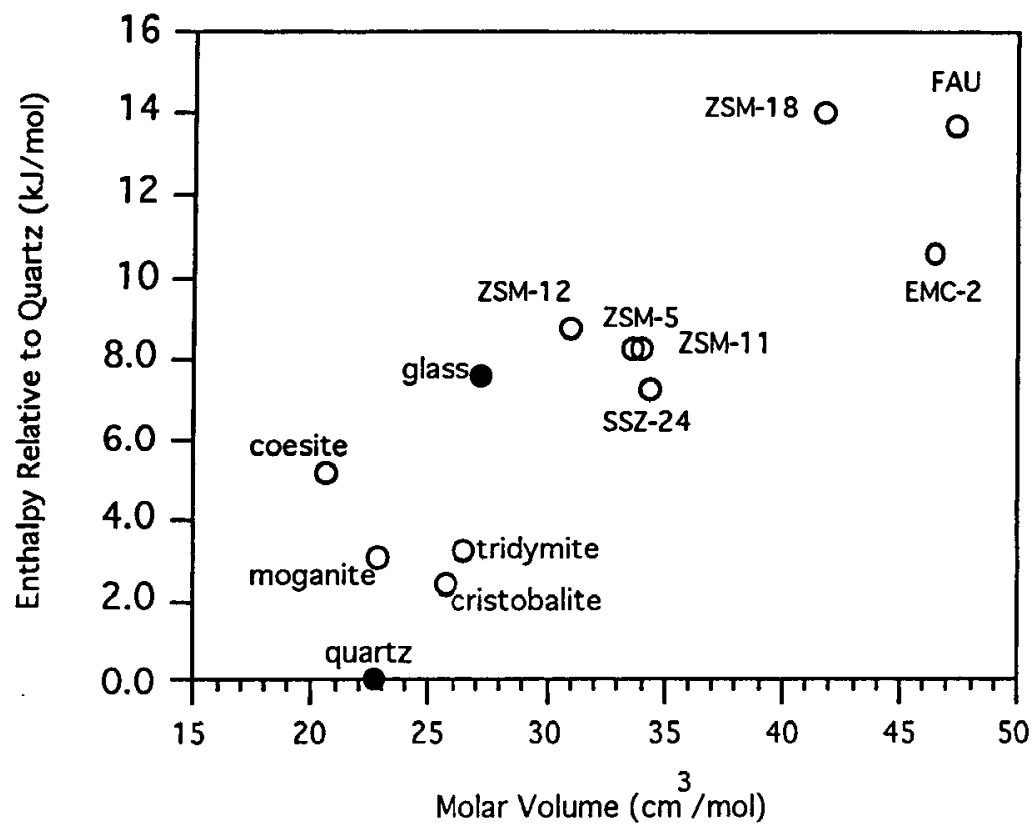

Figure 2 Enthalpy of formation of silicates relative to quartz vs molar volume. (Adapted from 22.)

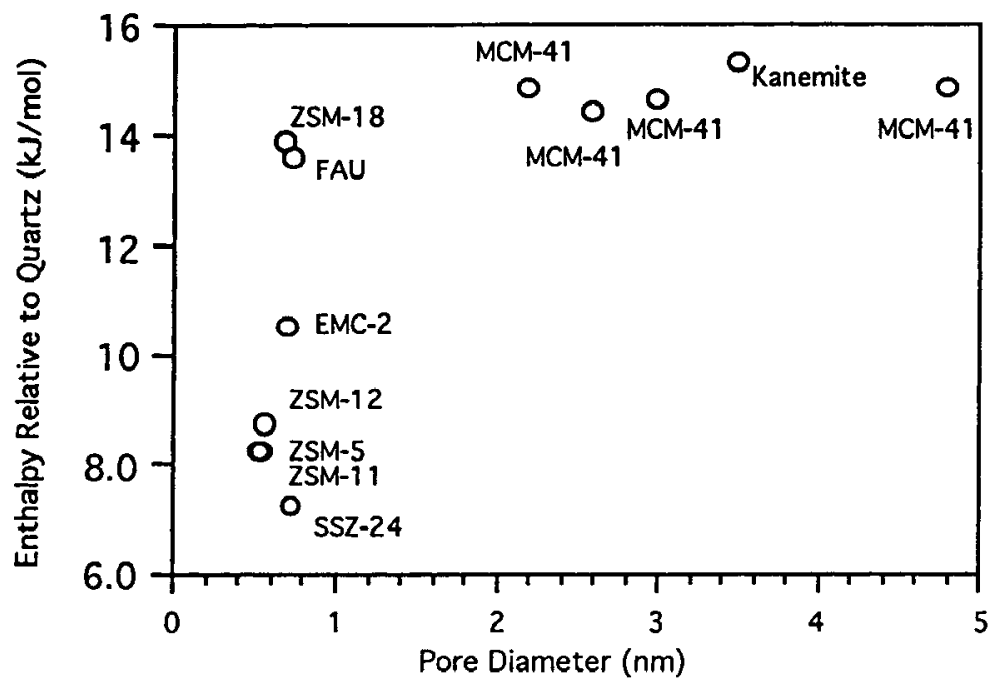

Figure 3 Enthalpy of formation of ordered mesoporous and zeolitic silicas relative to quartz vs pore diameter. (Adapted from 25.) 
in the energy of the crystal structure to one where large pores behave energetically as inert volumetric diluents. Because the large pores exist as a second phase, additional increases in pore diameter have little or no effect on the energy of the mesoporous silica. It should be noted that the mesoporous silicas are energetically similar to some high-silica zeolites, in spite of their large pore sizes and lack of crystallinity. It is also significant that the energy plateau is only $15 \mathrm{~kJ} / \mathrm{mol}$ above quartz.

For crystalline silicas, Petrovic et al (22) found no direct relationship between the enthalpy of formation and the framework density, mean Si$\mathrm{O}-\mathrm{Si}$ angle, or molar volume. In silicates, each silicon atom bonds with four oxygen atoms in a tetrahedral fashion; each oxygen atom connects two silicon atoms and the mean $\mathrm{Si}-\mathrm{O}-\mathrm{Si}$ angle is approximately $145^{\circ}$. Quantum mechanical calculations reveal a slight energy barrier to changes in the Si-O-Si angle between $140^{\circ}$ and $180^{\circ}$, but angles below $135^{\circ}$ experience a marked increase in energy (27). Thus, it is not surprising that all silicates have very similar energies. Petrovic and co-workers indicate that there is a correlation between the enthalpy of formation of silicates and the percentage of $\mathrm{Si}-\mathrm{O}-\mathrm{Si}$ angles below $140^{\circ}$. The correlation is consistent with the potential energy curve of the $\mathrm{Si}-\mathrm{O}-\mathrm{Si}$ angle and implies that the small angles have a more pronounced destabilizing effect than large angles. One note of caution is that numerous bond angles obtained from Rietveld refinements of powder X-ray diffraction data may not accurately represent the angles of the structure. Lobo et al (14) recommend withholding further conclusions until single crystal X-ray data become available, or until other analytical techniques confirm some of the surprising bond angles and lengths reported in the open literature.

\section{Thermodynamic Analysis of Pure-Silica ZSM-5 Synthesis}

Zeosils are thermodynamically metastable phases. However, zeosils could conceivably be formed from quartz, e.g.

$$
\text { quartz }+4 \mathrm{TPA}^{+} \mathrm{F}^{-}(\mathrm{aq}) \rightarrow \mathrm{TPA}^{+} \mathrm{F}^{-}-\mathrm{ZSM}-5+\mathrm{H}_{2} \mathrm{O},
$$

where ZSM-5 is the pure-silica version of this zeolite. How could this be? The important issue is that the thermodynamics of the complete synthesis mixture must be considered.

The above reaction can be written as the sum of two reactions:

$$
\begin{aligned}
& \text { quartz } \rightarrow \text { ZSM-5 } \\
& \text { ZSM-5 + } 4 \mathrm{TPA}^{+} \mathrm{F}^{-} \text {(aq) } \rightarrow \mathrm{TPA}^{+} \mathrm{F}^{-}-\mathrm{ZSM}-5+\mathrm{H}_{2} \mathrm{O}
\end{aligned}
$$

[the stoichiometric coefficient for $\mathrm{TPA}^{+} \mathrm{F}^{-}(\mathrm{aq})$ is 4 because $4 \mathrm{TPA}^{+} \mathrm{F}^{-}$ ion pairs are occluded in each unit cell of pure-silica ZSM-5]. 
Johnson et al provide thermodynamic properties for Reaction 1 at temperatures of 298.15 and $1000 \mathrm{~K}(28-31)$. The values at $298.15 \mathrm{~K}$ will be used as a lower bound for the feasibility of the reaction, since the change in Gibbs function is less at $1000 \mathrm{~K}$ (typical synthesis conditions involve temperatures of $400-500 \mathrm{~K}$ ). The thermodynamic parameters for Reaction 1 are

$\Delta \mathrm{H}=5.5 \mathrm{~kJ} / \mathrm{mol} \mathrm{SiO}_{2}$

$\mathrm{T} \Delta \mathrm{S}=1.4 \mathrm{~kJ} / \mathrm{mol} \mathrm{SiO}_{2}$

$\Delta \mathrm{G}($ reaction 1$)=\Delta \mathrm{H}-\mathrm{T} \Delta \mathrm{S}=4.1 \mathrm{~kJ} / \mathrm{mol} \mathrm{SiO}_{2}$.

Because $\Delta \mathrm{G}>0$, this process cannot spontaneously occur. Although the positive entropy favors Reaction 1, the large positive enthalpy hinders the transformation of quartz to pure-silica ZSM-5.

Partarin et al (32) determined that the change in enthalpy for Reaction 2 is $\Delta \mathrm{H}$ (reaction 2$)=-6.2 \mathrm{~kJ} / \mathrm{mol} \mathrm{SiO}_{2}$. To estimate the change in entropy for this process, the work of Johnson \& Martin (33) can be used. The standard entropy of solution for the salt $\mathrm{TPA}^{+} \mathrm{I}^{-}$was determined to be $\Delta \mathrm{S}$ (solution, $\mathrm{TPA}^{+} \mathrm{I}^{-}$) $=11 \mathrm{~J} / \mathrm{K}-\mathrm{mol} \mathrm{TPA}^{+} \mathrm{I}^{-}$for the following process:

$$
\mathrm{TPA}^{+} \mathrm{I}^{-}(\mathrm{s})+\mathrm{H}_{2} \mathrm{O} \rightarrow \mathrm{TPA}^{+} \mathrm{I}^{-}(\mathrm{aq}) \text {. }
$$

Here, we are concerned with the following reaction:

$$
\mathrm{TPA}^{+} \mathrm{F}^{-}(\mathrm{s})+\mathrm{H}_{2} \mathrm{O} \rightarrow \mathrm{TPA}^{+} \mathrm{F}^{-}(\mathrm{aq}) \text {. }
$$

To determine the entropy of solution for $\mathrm{TPA}^{+} \mathrm{F}^{-}(\mathrm{s})$, a thermodynamic cycle can be constructed such that $\triangle \mathrm{S}$ (solution, $\mathrm{TPA}^{+} \mathrm{F}^{-}$) can be estimated from the following equation:

$$
\begin{aligned}
\Delta \mathrm{S} \text { (solution, } & \left.\mathrm{TPA}^{+} \mathrm{F}^{-}\right)=\Delta \mathrm{S} \text { (solution, } \mathrm{TPA}^{+} \mathrm{I}^{-} \text {) } \\
& \left.\left.+\mathrm{S}\left[\mathrm{F}^{-}(\mathrm{aq})\right]-\mathrm{S}^{-} \mathrm{I}^{-}(\mathrm{aq})\right]+\mathrm{S}\left[\mathrm{TPA}^{+} \mathrm{F}^{-}(\mathrm{s})\right]-\mathrm{S}_{\mathrm{TPA}}^{+} \mathrm{I}^{-}(\mathrm{s})\right] .
\end{aligned}
$$

The absolute entropies for aqueous ions were obtained from Marcus (33) and are $\mathrm{S}\left[\mathrm{F}^{-}(\mathrm{aq})\right]=8.4 \mathrm{~J} / \mathrm{K}-\mathrm{mol} \mathrm{F}{ }^{-}$and $\left.\mathrm{S}^{-} \mathrm{I}^{-}(\mathrm{aq})\right]=133.5 \mathrm{~J} / \mathrm{K}-\mathrm{mol} \mathrm{I}$, so that $\mathrm{S}\left[\mathrm{F}^{-}(\mathrm{aq})\right]-\mathrm{S}\left[\mathrm{I}^{-}(\mathrm{aq})\right]=-125.1 \mathrm{~J} / \mathrm{K}-\mathrm{mol}$ halide anion. Johnson \& Martin calculated S[TPA $\left.{ }^{+} I^{-}(\mathrm{s})\right]$. We have not found any absolute entropy data for $\mathrm{TPA}^{+} \mathrm{F}^{-}(\mathrm{s})$. As a result, the difference in entropy between $\mathrm{TPA}^{+} \mathrm{F}^{-}(\mathrm{s})$ and $\mathrm{TPA}^{+} \mathrm{I}^{-}(\mathrm{s})$ is estimated using a procedure from Lewis \& Randall's text, as revised by Pitzer \& Brewer (34). This estimation assumes that the force constants restraining atomic motion are similar for the fluorine and iodine atoms as they exist in the compounds $\mathrm{TPA}^{+} \mathrm{F}^{-}(\mathrm{s})$ and 
$\mathrm{TPA}^{+} \mathrm{I}^{-}(\mathrm{s})$ and implies that the compressibility of fluorine is similar to that of iodine in the tetrapropylammonium salts. This approximation is rigorous enough that it does not require similar force constants for elemental (or molecular) fluorine and iodine; only the behavior of these elements in the compounds is important. [Although the validity of this assumption regarding force constants is questionable, it is one of the few, or only, alternatives available in the absence of absolute entropy data for $\mathrm{TPA}^{+} \mathrm{F}^{-}(\mathrm{s})$. The results of such analysis should be evaluated with caution.] The approximation used here applies to compounds differing in the replacement of 1 atom and is

$$
\left.\mathrm{S} \mathrm{TPA}^{+} \mathrm{F}^{-}(\mathrm{s})\right]-\mathrm{S}\left[\mathrm{TPA}^{+} \mathrm{I}^{-}(\mathrm{s})\right]=3 / 2 \mathrm{R} \ln \left(M_{\mathrm{F}} / M_{\mathrm{l}}\right),
$$

where $\mathrm{R}$ is the universal gas constant, $M_{\mathrm{F}}$ the atomic weight of fluorine, and $M_{\mathrm{I}}$ the atomic weight of iodine. The result from this calculation gives

$$
\left.\mathrm{S}_{\mathrm{TPA}}{ }^{+} \mathrm{F}^{-}(\mathrm{s})\right]-\mathrm{S}\left[\mathrm{TPA}^{+} \mathrm{I}^{-}(\mathrm{s})\right]=-23.7 \mathrm{~J} / \mathrm{K}-\mathrm{mol} \text { salt. }
$$

Substituting the aforementioned values into the thermodynamic cycle used to calculate the entropy of solution for $\mathrm{TPA}^{+} \mathrm{F}^{-}(\mathrm{s})$ gives

$$
\Delta \mathrm{S}\left(\text { solution, } \mathrm{TPA}^{+} \mathrm{F}^{-}\right)=-137.5 \mathrm{~J} / \mathrm{K}-\mathrm{mol} \mathrm{TPA}^{+} \mathrm{F}^{-}
$$

or

$$
\Delta \mathrm{S}\left(\text { solution, } \mathrm{TPA}^{+} \mathrm{F}^{-}\right)=-5.7 \mathrm{~J} / \mathrm{K}-\mathrm{mol} \mathrm{SiO}_{2},
$$

(the remaining values are expressed in terms of $\mathrm{mol} \mathrm{SiO}_{2}$; there are $96 \mathrm{SiO}_{2}$ formula units and $4 \mathrm{TPA}^{+} \mathrm{F}^{-}$ion pairs in one unit cell of ZSM-5).

Consider the reverse of Reaction 4:

$$
\mathrm{TPA}^{+} \mathrm{F}^{-}(\mathrm{aq}) \rightarrow \mathrm{TPA}^{+} \mathrm{F}^{-}(\mathrm{s})+\mathrm{H}_{2} \mathrm{O} ; \quad \Delta \mathrm{S}=5.7 \mathrm{~J} / \mathrm{K}-\mathrm{mol} \mathrm{SiO}{ }_{2} .
$$

At $298 \mathrm{~K}, \mathrm{~T} \Delta \mathrm{S}$ (Reaction 5) $=1.7 \mathrm{~kJ} / \mathrm{mol} \mathrm{SiO}_{2}$.

The entropy change for Reaction 5 can be used as an approximation for the change in entropy for Reaction 2 if one assumes that the entropy change for the organic $\mathrm{TPA}^{+} \mathrm{F}^{-}$going from the aqueous phase into the zeolite is identical to that for transfer from an aqueous phase into a pure crystalline phase of $\mathrm{TPA}^{+} \mathrm{F}^{-}$. This assumption is subject to criticism, but is preferable to the alternative of statistical mechanical calculations involving other questionable assumptions. The disordering of water and the ordering of $\mathrm{TPA}^{+} \mathrm{F}^{-}$are both accounted for in this estimate of the change in entropy for Reaction 2. (The concept of water ordering around organic molecules is discussed below.) It is also assumed that the entropy of the ZSM-5 framework is the same whether the TPA ${ }^{+} \mathbf{F}^{-}$is occluded or 
not. Thus any changes in the entropy due to distortions in the crystal structure caused by the occluded $\mathrm{TPA}^{+} \mathrm{F}^{-}$ion pairs are neglected.

Using the enthalpy and entropy data for Reaction 2, one finds

$$
\Delta \mathrm{G}\left(\text { Reaction 2) }=\Delta \mathrm{H}-\mathrm{T} \Delta \mathrm{S}=-7.9 \mathrm{~kJ} / \mathrm{mol} \mathrm{SiO}_{2}\right. \text {. }
$$

The large negative value of $\Delta \mathrm{H}$ (which favors the process) and the smaller negative value of $T \Delta S$ (which also favors the process) result in a negative value for the change in Gibbs function. The cause of the large magnitude of the exothermic enthalpy is the contribution of the $\mathrm{TPA}^{+} \mathrm{F}^{-}$ion pairs to the energetic stabilization of the TPA ${ }^{+} \mathrm{F}^{-}-\mathrm{ZSM}-5$ composite. The tight fit of the TPA ${ }^{+}$ions inside the channels of ZSM-5 and the resulting large number of van der Waais contacts makes the tetrapropylammonium cation a powerful structure-directing agent in the synthesis of ZSM-5.

The increase in entropy accompanying Reaction 2 (and Reaction 5) can be understood in terms of the disordering of water that takes place during this process. Again, consider Reaction 4. As mentioned by Tanford (35), the formation of ionic solutions in water often results in a decrease in entropy, as ion-dipole forces cause an ordering of water molecules around the ions. Frank \& Evans (36) explained the entropy decrease that occurs when a hydrocarbon is dissolved in water as a tightening of the structure of water around the hydrocarbon molecules. Lindenbaum \& Boyd (37) extended this argument to tetraalkylammonium halides. The nonpolar alkyl groups of the quaternary ammonium cations order the water molecules around the tetraalkylammonium ions (see Figure 4). As the alkyl chains increase in length, the ions become more hydrophobic and further promotes water ordering. Krishnan \& Friedman (38) have reported on the

(a)

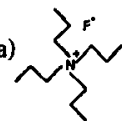

(b)

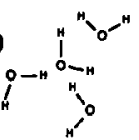

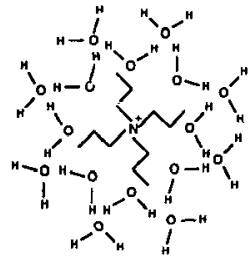

Water Ordering Around TPA+F-(aq) upon combining

(a) and (b)
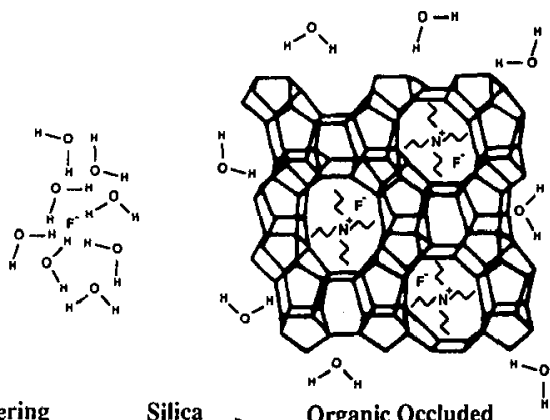

in ZSM-5,

$\mathrm{H}_{2} \mathrm{O}$ outside crystal
Salt and Water
(a) $\operatorname{TPA}^{+} \mathrm{F}^{*}(\mathrm{~s})$

(b) $\mathrm{H}_{2} \mathrm{O}$

Figure 4 Ordering and disordering of water molecules around organic structure-directing agents. 
water structure-making effects of tetrapropylammonium and tetrabutylammonium $\left(\mathrm{TBA}^{+}\right)$cations, and Frank \& Wen (39) mention the structure-promoting ability of tetrabutylammonium cations. Based on the above discussion for Reaction 4, the disordering of water in Reaction 5 should result in an increase in the entropy of the system, which would contribute to a more negative change in the Gibbs function. These qualitative arguments agree with the calculations shown above.

Combining Reactions 1 and 2 to achieve the overall zeolite synthesis reaction,

$$
\Delta \mathrm{G} \text { (overall process) }=-3.8 \mathrm{~kJ} / \mathrm{mol} \mathrm{SiO}_{2} \text {. }
$$

Since $\Delta G<0$, this process is thermodynamically possible. It is worth noting that Petrovic et al (22) determined the change in enthalpy for Reaction 1 to be $\Delta \mathrm{H}=8.2 \mathrm{~kJ} / \mathrm{mol} \mathrm{SiO}_{2}(22)$, which is $2.7 \mathrm{~kJ} / \mathrm{mol} \mathrm{SiO}_{2}$ higher than the value calculated by Johnson et al $\left(\Delta \mathrm{H}=5.5 \mathrm{~kJ} / \mathrm{mol} \mathrm{SiO}_{2}\right)$. If the value from Petrovic et al is used,

$\Delta \mathrm{G}$ (overall process) $=-1.1 \mathrm{~kJ} / \mathrm{mol} \mathrm{SiO}{ }_{2}$.

Although this is a low thermodynamic driving force, the change in Gibbs function is still less than zero. Thus the process is thermodynamically feasible.

It should be noted that these calculations involved data from several sources that were working with different systems, as well as some debatable assumptions. The exact numerical values are not as crucial as the trends in $\Delta \mathrm{G}$; the important point is that the transformation from quartz to ZSM-5 is thermodynamically possible with the addition of tetrapropylammonium fluoride.

Consider another synthesis of pure-silica ZSM-5, one that is more common than that involving quartz as a starting material:

$$
\text { glass }+4 \mathrm{TPA}^{+} \mathrm{F}^{-}(\mathrm{aq}) \rightarrow \mathrm{TPA}^{+} \mathrm{F}^{-}-\mathrm{ZSM}-5 \text {. }
$$

This conversion can also be written as the sum of two reactions:

$$
\begin{aligned}
& \text { glass } \rightarrow \mathrm{ZSM}-5 \\
& \mathrm{ZSM}^{-5}+4 \mathrm{TPA}^{+} \mathrm{F}^{-}(\mathrm{aq}) \rightarrow \mathrm{TPA}^{+} \mathrm{F}^{-}-\mathrm{ZSM}-5 .
\end{aligned}
$$

Referring again to the work of Johnson et al, and using thermodynamic data applicable at $298.15 \mathrm{~K}$, the thermodynamic quantities for Reaction 6 are

$$
\begin{aligned}
& \Delta \mathrm{H}=-3.65 \mathrm{~kJ} / \mathrm{mol} \mathrm{SiO}_{2} \\
& \mathrm{~T} \Delta \mathrm{S}=-0.66 \mathrm{~kJ} / \mathrm{mol} \mathrm{SiO}_{2}
\end{aligned}
$$


$\Delta \mathrm{G}($ Reaction 6$)=\Delta \mathrm{H}-\mathrm{T} \Delta \mathrm{S}=-3.0 \mathrm{~kJ} / \mathrm{mol} \mathrm{SiO}_{2}$.

From a thermodynamic standpoint, Reaction 6 can spontaneously occur. Pure-silica ZSM-5 is more stable than glass (which is amorphous silica), even without any occluded organic molecules.

Reaction 7 enhances the transformation of glass to ZSM-5. Using the change in enthalpy for Reaction 7 given by Patarin et al $(\Delta \mathrm{H}=-6.2$ $\mathrm{kJ} / \mathrm{mol} \mathrm{SiO}_{2}$ ) and the estimate for the change in entropy as described above $\left(\mathrm{T} \Delta \mathrm{S}=1.7 \mathrm{~kJ} / \mathrm{mol} \mathrm{SiO}_{2}\right)$,

$$
\Delta \mathrm{G}\left(\text { Reaction 7) }=\Delta \mathrm{H}-\mathrm{T} \Delta \mathrm{S}=-7.9 \mathrm{~kJ} / \mathrm{mol} \mathrm{SiO}_{2} .\right.
$$

Combining Reactions 6 and 7 to achieve the overall reaction,

$$
\Delta \mathrm{G} \text { (overall process) }=-10.9 \mathrm{~kJ} / \mathrm{mol} \mathrm{SiO}_{2} \text {. }
$$

Because the change in Gibbs function is well below zero, this process has a strong thermodynamic driving force. As is true for the example involving quartz, these calculations should be used with caution.

One implication for the synthesis of zeolites by design that can be obtained from the results of this analysis is that the "goodness of fit" of the organic structure-directing agent inside the pores of the zeolite is an important component of the thermodynamic driving force for the process. For Reaction 2 ; $\Delta \mathrm{H}=-6.2 \mathrm{~kJ} / \mathrm{mol} \mathrm{SiO}_{2}$. This term relates to the interaction energy between the organic molecule and the inorganic silicate, and its magnitude dominates the entropic contribution. Thus it provides a first-order approximation for the change in Gibbs function of the process. From geometric considerations, it is known that the $\mathrm{TPA}^{+} \mathrm{F}^{-}$ion pairs fit tightly into the ZSM-5 void space. If the organic molecules do not fit as well inside the void spaces, the number of van der Waals interactions will be reduced, and $\Delta \mathrm{H}$ should be more positive (less favorable energetics). Therefore, the entropic driving force (release of ordered water) will become more important as the interactions between the organic and silica framework decline.

Burkett \& Davis (40) have synthesized pure-silica ZSM-5 in less than a week, using $\mathrm{TPA}^{+} \mathrm{OH}^{-}$as the structure-directing agent. However, they were unable to prepare ZSM-5 with tetraethanolammonium hydroxide, $\left(\mathrm{HOC}_{2} \mathrm{H}_{4}\right)_{4} \mathrm{~N}^{+} \mathrm{OH}^{-}$, even after one month at hydrothermal synthesis conditions. Wen \& Saito $(41,42)$ have shown that the size of the tetraethanolammonium cation is similar to that of the tetrapropylammonium cation. Thus the "goodness of fit" of the organic inside the zeolite pores does not by itself determine whether a particular synthesis can occur (although the sizes are similar, the interaction energies are most likely slightly different). Frank \& Wen (39) predicted that solutes with $\mathrm{OH}$ groups will not significantly affect the structure of water due to the similar 
hydrogen-bonding characteristics of water and alcohols. Wen \& Saito also claim that quaternary ammonium cations with terminal hydroxyl groups will have less influence on the structure of water than the equivalent tetraalkylammonium cations. Results from Agar (43), Price (44), and H Frank \& W Wen (unpublished data) agree with the claim of Wen \& Saito. Since $\left(\mathrm{HOC}_{2} \mathrm{H}_{4}\right)_{4} \mathrm{~N}^{+} \mathrm{OH}^{-}$does not order water like $\mathrm{TPA}^{+} \mathrm{OH}^{-}$, syntheses involving tetraethanolammonium hydroxide will not have the same entropic driving force that is present in syntheses using $\mathrm{TPA}^{+} \mathrm{OH}^{-}$. Thus on first inspection, the necessity of water ordering may be the critical factor. However, at this time not enough information exists to decouple the enthalpic and entropic driving forces in zeolite syntheses, since the precise interaction energies for tetraethanolammonium ions in ZSM-5 is unknown.

One must exercise caution when attempting to extend the thermodynamic analysis of zeolite synthesis involving fluoride to one using hydroxide anions. With a synthesis of pure-silica ZSM-5 using TPA ${ }^{+} \mathrm{F}^{-}$ as the structure-directing agent, the fluoride anion is occluded inside the ZSM-5 void space along with the tetrapropylammonium cation. When $\mathrm{TPA}^{+} \mathrm{OH}^{-}$is used, the TPA ${ }^{+}$cation is occluded but the $\mathrm{OH}^{-}$anion is not. The positive charge of $\mathrm{TPA}^{+}$is balanced by a $\mathrm{Si}-\mathrm{O}^{-}$defect in the zeolite structure (14). The effect of the ZSM-5 structural defect, i.e. Si-O- ${ }^{-}$, on the thermodynamics of the synthesis process is unknown at this time and should be investigated.

\section{Energetic Interactions of Organic Structure-Directing Agents with Silicates}

Pure-silica zeolites are hydrophobic and have unfavorable interactions with water molecules. Additionally, zeolites in aqueous solution are thermodynamically less stable than dense phases. When organic molecules are occluded in the micropores of the zeolite, water penetration decreases and favorable interactions occur between the silica wall of the zeolite and the occluded organic molecules. It has been speculated that, via these silicaorganic interactions, pure-silica zeolites attain enough thermodynamic stability to exist (45). Petrovic et al (22) showed experimentally that this is not the case. Rather, the organic structure-directing agents assist in selecting which zeolite will be formed from a wide range of energetically feasible possibilities (see below). For these favorable interactions to occur, a good fit between the organic molecule and the zeolite void space is required, i.e. the number of van der Waals contacts is maximized. As a result, syntheses involving organic structure-directing agents often yield pure-silica zeolites with pore dimensions and shapes similar to those of the organic molecules. 


\section{HELMKAMP \& DAVIS}

Patarin and co-workers studied the energetic contribution of propylammonium species to the stabilization of ZSM-5 (32). Although several organic structure-directing agents can be used to synthesize ZSM-5, TPA ${ }^{+}$ cations are the most efficient. Patarin et al synthesized three high-silica ZSM-5 samples in the presence of DIPA ${ }^{+}$, TRIPA ${ }^{+}$, and TPA ${ }^{+}$cations: $\left(\mathrm{C}_{3} \mathrm{H}_{7}\right)_{2} \mathrm{NH},\left(\mathrm{C}_{3} \mathrm{H}_{7}\right)_{3} \mathrm{~N}$, and $\left[\left(\mathrm{C}_{3} \mathrm{H}_{7}\right)_{4} \mathrm{~N}\right]^{+} \mathrm{Br}^{-}$, respectively. $\mathrm{NH}_{4} \mathrm{~F}$ was used with $\mathrm{TPA}^{+}$, and hydrofluoric acid (HF) was used with $\mathrm{TRIPA}^{+}$and $\mathrm{DIPA}^{+}$to form $\mathrm{TPA}^{+} \mathrm{F}^{-}$, TRIPAH ${ }^{+} \mathrm{F}^{-}$, and $\mathrm{DIPAH}^{+} \mathrm{F}^{-}$. By determining the solution enthalpy in $25 \% \mathrm{HF}$, the standard enthalpy of formation was determined for each organic-inorganic material (all have the structure of ZSM-5). The contribution of the organic molecule to the stabilization of the composite (organic-inorganic) structure was estimated. As expected, DIPA ${ }^{+}$and TRIPA ${ }^{+}$were shown to stabilize the composite less than $\mathrm{TPA}^{+}$. The interaction between the organic species and the zeolite framework was significant in the case of $\mathrm{TPA}^{+}$only, which is due in part to the tight fit of $\mathrm{TPA}^{+}$in the zeolite void space.

Although the work by Patarin et al illustrates the energetic stabilization that an organic molecule can provide, the close proximity of enthalpies of formation of various silicates suggests that the organic structure-directing agent may play more of a kinetic role than a thermodynamic one in the synthesis process (14). It should be noted, though, that the presence of the organic molecule inside the void space of the silicate lowers the total Gibbs function of formation of the complete synthesis mixture. This process is analogous to the reduced total Gibbs function of formation of a solution of two miscible fluids when compared with the sum of the free energies of the individual components.

Next, we consider the energetic favorability (or lack thereof) of the organic molecule occluded inside the pores of the silicate. Organic structure-directing agents are water-soluble molecules. Shimizu \& Taniguchi $(46,47)$ have shown that tetrapropylammonium $\left(\mathrm{TPA}^{+}\right)$ions have mainly hydrophobic interactions with water, in spite of the positive charge [tetramethylammonium $\left(\mathrm{TMA}^{+}\right)$ions are hydrophilic, and tetraethylammonium $\left(\mathrm{TEA}^{+}\right)$ions are intermediate in behavior]. The longer hydrocarbon chains on $\mathrm{TPA}^{+}$account for its hydrophobicity compared to $\mathrm{TMA}^{+}$. The energetic gains achieved from the solvation of the positive charge are partially offset by the entropic cost of ordering water around $\mathrm{TPA}^{+}$. The propyl groups of TPA ${ }^{+}$prefer to interact with the hydrophobic silicate species rather than water molecules $(48,49)$. Thus water molecules around $\mathrm{TPA}^{+}$ions should be readily displaced by silicate ions when $\mathrm{TPA}^{+}(\mathrm{aq})$ is contacted with water-soluble silicate species. For the smaller alkyl groups on $\mathrm{TMA}^{+}$, such interactions with silicates do not occur (49).

The structure-directing effects of TPA ${ }^{+}$were investigated by Burkett \& 
Davis (49), who probed the mechanism of structure-direction in the synthesis of ZSM-5 using solid-state NMR. ${ }^{1} \mathrm{H}^{-29} \mathrm{Si}$ CP MAS NMR was performed between the protons of TPA ${ }^{+}$(the organic used) and the silicon atoms of the forming zeolite in a deuterated synthesis gel. This work shows the first direct evidence that preorganized organic-inorganic composites form during the synthesis of pure-silica ZSM-5. The high efficiency of polarization transfer observed after one day of hydrothermal synthesis indicates that there are significant interactions between the silicate species and the $\mathrm{TPA}^{+}$ions at this stage of the synthesis, where no evidence of ZSM-5 crystals exists by either IR or X-ray diffraction techniques. For this type of energy transfer to occur in the NMR experiment, the protons on the $\mathrm{TPA}^{+}$cation must be within a van der Waals contact distance of the silicon atoms. Burkett \& Davis propose that the organic-inorganic composites take part in nucleation and subsequent crystal growth and that they participate in crystal growth via diffusion to the surface of the growing crystallites (see Figure 5). This mechanistic proposal can account for the layer-by-layer growth inferred from the intergrowth frameworks of ZSM-5/ZSM-11, SSZ-26/SSZ-33/CIT-1 (14, 50, 51), and zeolite beta (52, 53).

Zones investigated the interactions between water and organic molecules with a variety of structure-directing agents by studying the transfer of organic molecules to a chloroform phase from an aqueous phase for varying $\mathrm{C} / \mathrm{N}^{+}$ratios (14). The amount of organic transferred was large $(>70 \%)$ for molecules with $\mathrm{C} / \mathrm{N}^{+}>15$ and low $(<10 \%)$ for those with $\mathrm{C} / \mathrm{N}^{+}<11$ (see Figure 6). When using structure-directing agents with $11<\mathrm{C} / \mathrm{N}^{+}<15$, a large number of high-silica zeolites have been synthesized. These data suggest that a desirable organic structure-directing agent should be somewhat soluble in both the water and silica phases. Gerke et al (54) drew a similar conclusion, namely that the organic guest should not form strong complexes with the solvent used.

\section{KINETICS}

When a silicate less stable than quartz is formed without the occlusion of a structure-directing agent, it is clear that the synthetic process is kinetically controlled. For example, tridymite and cristobalite are frequently prepared when one is attempting to synthesize a high-silica zeolite. [Griffen showed that these dense silicates have less thermodynamic stability than quartz at synthesis conditions (55).] Since cristobalite and tridymite are commonly obtained, the kinetics of crystallization determine the product of the synthesis. 
Annual Reviews

www.annualreviews.org/aronline

176

HELMKAMP \& DAVIS<smiles>C=CCC[N+](CCC)(CCC)CCC</smiles>
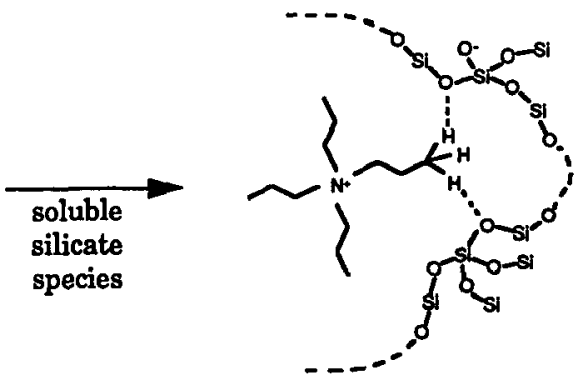

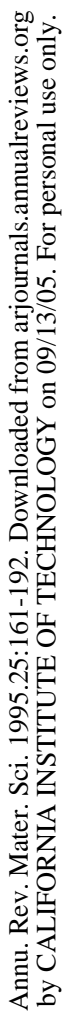
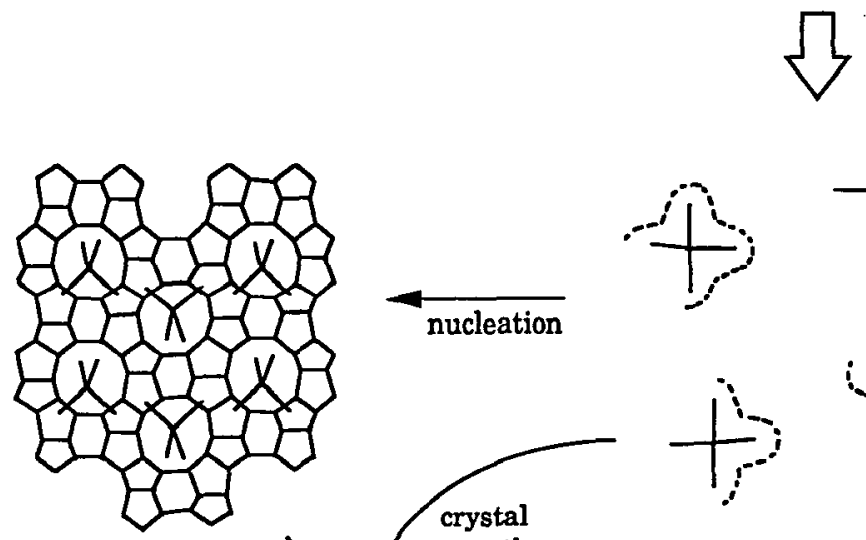

nucleation
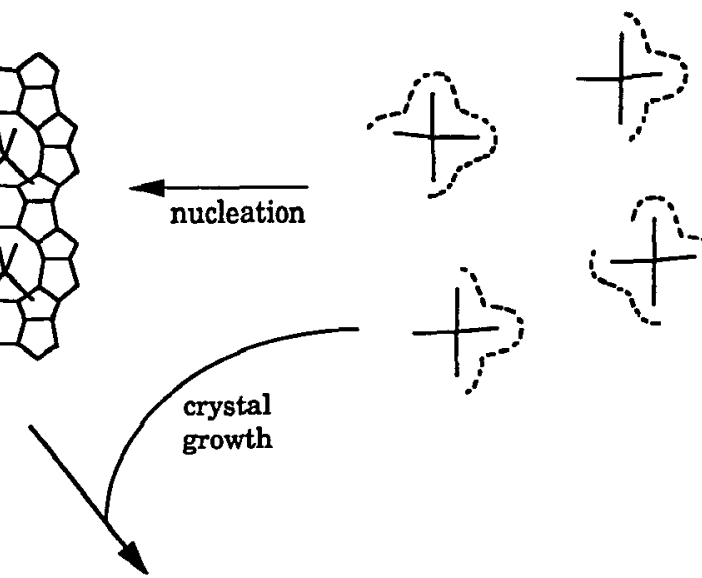

crystal growth

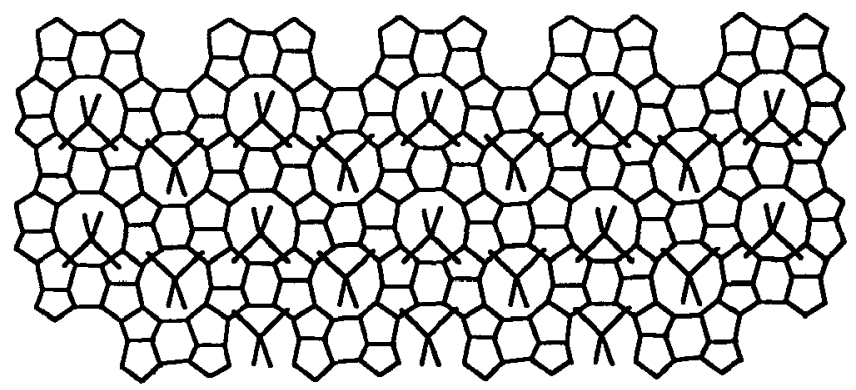

Figure 5 Proposed mechanism of structure-direction and crystal growth involving organicinorganic composites in the synthesis of pure-silica ZSM-5 using $\mathrm{TPA}^{+}$as structure-directing agent. (Adapted from 49.) 


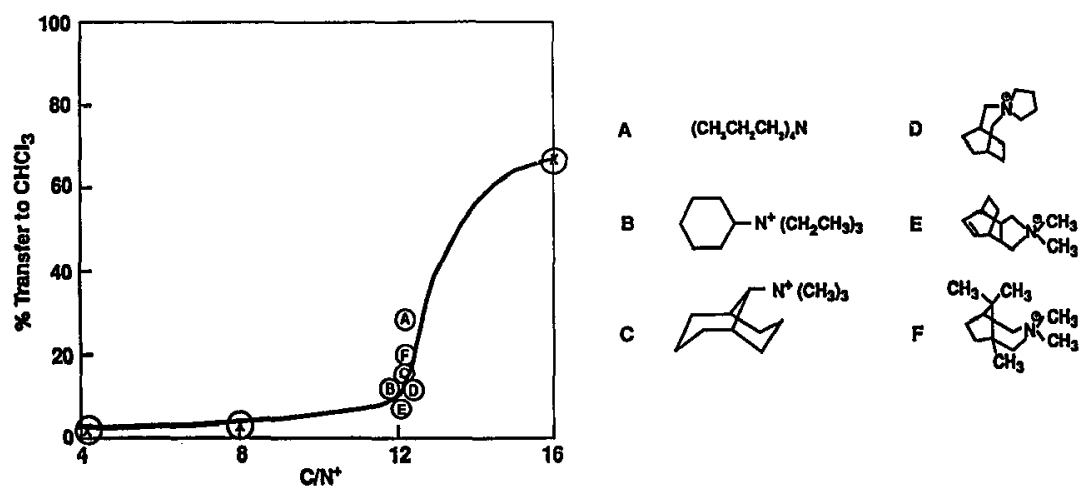

Figure 6 The percent transfer of organic molecules into a chloroform phase from an aqueous phase for varying $\mathrm{C} / \mathrm{N}^{+}$ratios. (Adapted from 14.)

\section{Effects of Structure-Directing Agent on Crystallization Rate}

When an organic molecule is included in a synthesis mixture, otherwise identical synthesis gels with different organic structure-directing agents can yield completely different zeolites. For example, SSZ-24 and ZSM-5 are similar energetically (22), but the former is synthesized using TMADAOH (N,N,N-trimethyl 1-adamantammonium hydroxide) as the organic, whereas the latter is formed using $\mathrm{TPA}^{+} \mathrm{OH}^{-}$.

The choice of a structure-directing agent can affect the rate of crystallization. Harris \& Zones (56) investigated the guest/host energetics for the synthesis of the clathrasil nonasil and the zeolite SSZ-13. They suggest that a rate-determining step for the nucleation of nonasil and SSZ-13 is the interaction of the structure-directing agent with the inorganic gel. Puresilica clathrasil syntheses where the organic structure-directing molecule is similar in size to the inorganic cage of the final product have faster nucleation rates than those experiments where the size-matching is not as good. This result shows the importance of a tight fit for the structuredirecting agent inside the clathrasil cage for fast nucleation rates.

\section{Effects of Alkali Metal Cations on Zeolite Synthesis}

The presence of alkali metal cations is required for the vast majority of zeolite syntheses at basic conditions (ZSM-11 and ZSM-5 are exceptions and can be synthesized using $\mathrm{TBA}^{+}$and $\mathrm{TPA}^{+}$as the structure-directing agents with no alkali metal cations in the synthesis gel). The synthesis of pure-silica ZSM-12 was carried out with and without alkali metal cations at constant hydroxide concentration by Goepper et al (57). Their results indicate that alkali metal ions, e.g. $\mathrm{K}^{+}$or $\mathrm{Na}^{+}$, are required to synthesize pure-silica ZSM-12 in 7 days at $423 \mathrm{~K}$. Although $\mathrm{K}^{+}$and/or $\mathrm{Na}^{+}$are 
not needed to synthesize pure-silica ZSM-12, at constant hydroxide ion concentration, the rate of crystallization decreases as the ratio $\mathrm{K}^{+} / \mathrm{SiO}_{2}$ (or $\mathrm{Na}^{+} / \mathrm{SiO}_{2}$ ) declines. In the absence of $\mathrm{K}^{+}$, and using seed crystals of uncalcined ZSM-12, pure ZSM-12 can be formed in 14 days at $423 \mathrm{~K}$. Usually the use of seed crystals is believed to enhance nucleation alone. If the potassium ions added to the synthesis gel only participate in nucleation, then experiments with $\mathrm{K}^{+} / \mathrm{SiO}_{2}=0.3$, and no seeds should yield similar results to experiments with $\mathrm{K}^{+} / \mathrm{SiO}_{2}=0$ and $2 \% \mathrm{ZSM}-12$ seeds. Since the latter synthesis required twice as much time, it was concluded that the potassium ions participate in nucleation and crystal growth.

Goepper and co-workers eliminated the effects of ammonium cations contained in the Ludox AS-40 silica source by using fumed silica (Cab-OSil) in some trials. ZSM-12 was synthesized in 7 days using sodium cations, but the synthesis took $2 \frac{1}{2}$ months when no alkali metal ions were included. When ammonium hydroxide was present in the synthesis gel (in a concentration equal to that used in the sodium trials), no zeolite was formed after 14 days. These results indicate that sodium cations enhance the crystallization rate of pure-silica ZSM-12, but ammonium ions do not (at least not as much as sodium ions). It was observed that all of the ZSM-12 samples obtained from gels with different concentrations of potassium ions had similar morphologies; however, these morphologies were different from that of ZSM-12 synthesized in the absence of alkali cations. This result again suggests that alkali metal ions are involved in nucleation and crystal growth (16).

The role of potassium and sodium in zeolite synthesis can be understood further by the results of measuring the rate of dissolution of quartz into aqueous solutions of alkali metal cations. The dissolution of quartz in aqueous solutions of $\mathrm{KCl}, \mathrm{NaCl}, \mathrm{MgCl}_{2}$, and $\mathrm{LiCl}$ was studied by Dove \& Crerar (58) and Brady \& Walters (59). Small concentrations of electrolytes increased the dissolution rate up to 15 times as much as the rate in deionized water. Higher dissolution rates were obtained for $\mathrm{NaCl}$ and $\mathrm{KCl}$ compared with $\mathrm{MgCl}_{2}$ and $\mathrm{LiCl}$, which could be explained on the basis of capability for adsorption on the surface of quartz. Because $\mathrm{Li}^{+}$and $\mathrm{Mg}^{2+}$ have large charge-to-size ratios, they can coordinate well with water molecules and have reduced potentials for adsorption onto quartz. Applying this explanation to zeolite synthesis, one can conclude that potassium and sodium play a role in the polymerization and depolymerization of the silicate present in the synthesis gel. Through this process (as well as other possibilities), they can accelerate nucleation and growth rates of high-silica zeolite crystals.

Zones has studied the effects of sodium concentration on the synthesis of large-pore borosilicates (mainly silica) using endo and exo derivatives 
of tricyclo(5.2.1.0)decanes as organic structure-directing agents (60). At high alkali-metal ion concentrations, the sodium cations appear to compete with the organics as structure-directing agents. A layered silicate was obtained from high sodium concentrations, whereas zeolites were synthesized with lower amounts of sodium ion. Why do high sodium concentrations result in layered silicates? The answer is currently unknown, although the valence matching principle of Brown may be used to formulate a hypothesis (61). A bond valence approach to chemical structure and bonding would suggest that the most stable structures will be formed when the Lewis base strength of the anion is closest to the Lewis acid strength of the cation. Silicate anions can exist in the form of monomers $\left(\mathrm{Q}^{0}\right)$, dimers $\left(\mathrm{Q}^{1}\right)$, chain structures $\left(\mathrm{Q}^{2}\right)$, or layered structures $\left(Q^{3}\right)$. According to Figure $7(61)$, the best valence match for sodium ions occurs with a layered $\left(Q^{3}\right)$ silicate anion. As the ratio $\mathrm{Na}^{+} / \mathrm{Si}$ increases, the formation of a layered silicate becomes more likely.

The above examples illustrate the delicate balance that must be maintained in the synthesis gel to achieve the desired product in the shortest possible time. Alkali metal cations accelerate the rate of crystallization of

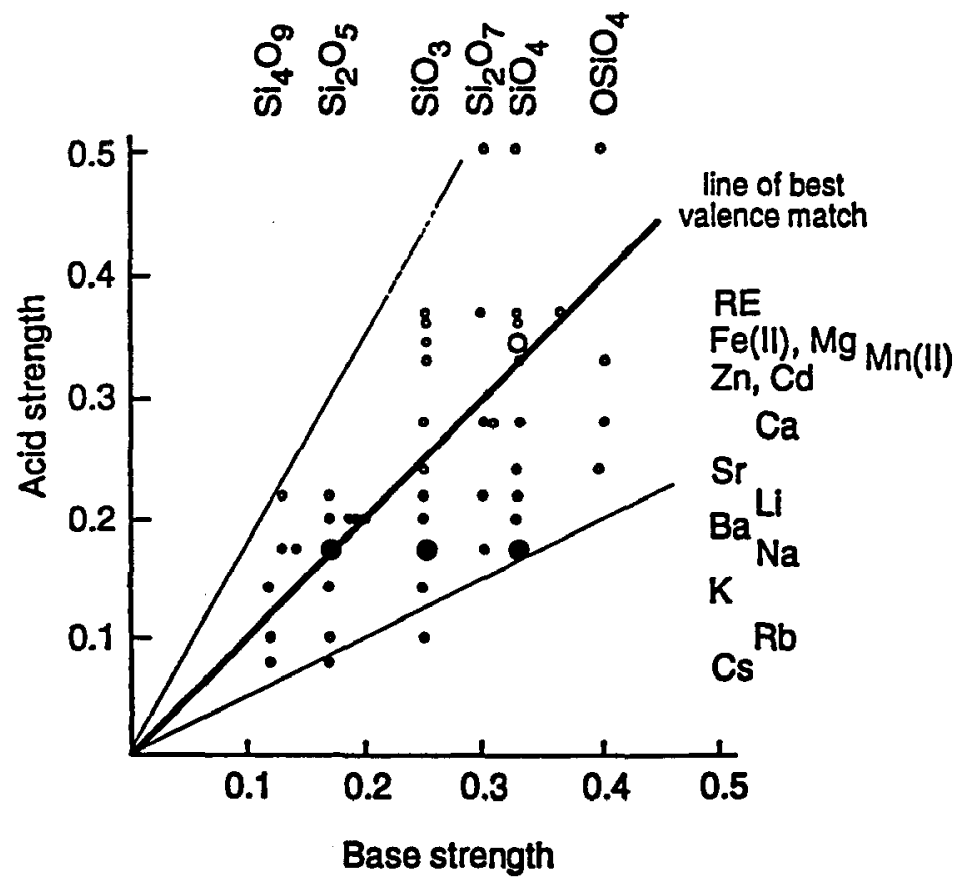

Figure 7 Silicate compounds as a function of the acid strengths and base strengths of the charge balancing cations. (Adapted from 61.) 
high-silica zeolites, but too much alkali metal ion may result in competition with the organic structure-directing agent for interactions with silica such that layered products can result.

\section{Effects of $\mathrm{O}-\mathrm{H}$ (or $\mathrm{O}-\mathrm{D}$ ) Bond Breaking on Nucleation Rate}

In addition to the structure-directing agent and alkali metal cations present in the synthesis gel, other factors can influence the nucleation rate. For example, Burkett \& Davis (40) have observed isotope effects in the syntheses of pure-silica ZSM-48 and ZSM-5 using fumed silica (Cab-O-Sil). A delay in nucleation is observed when $\mathrm{D}_{2} \mathrm{O}$ is used in place of $\mathrm{H}_{2} \mathrm{O}$ in the synthesis mixture. When the syntheses are conducted in the presence of $\mathrm{Na}^{+}$ions, the rates of nucleation are virtually indistinguishable for $\mathrm{D}_{2} \mathrm{O}$ and $\mathrm{H}_{2} \mathrm{O}$ and are enhanced relative to the sodium-free trials. Since $\mathrm{Na}^{+}$ ions have been shown to increase the rate of $\mathrm{SiO}_{2}$ dissolution, the dissolution of silica is believed to play a role in the delay of nucleation for $\mathrm{D}_{2} \mathrm{O}$ compared with $\mathrm{H}_{2} \mathrm{O}$. [Dutta et al (62) also noted a delay in the crystallization rate of zeolite $A$ when $\mathrm{D}_{2} \mathrm{O}$ was used instead of $\mathrm{H}_{2} \mathrm{O}$, even though sodium was present. They suggested that an isotope effect with the condensation polymerization reactions required for growth of zeolites may be responsible for this delay.] Because $\mathrm{OD}^{-}$is a stronger base than $\mathrm{OH}^{-}$, silica should be dissolved more rapidly in $\mathrm{D}_{2} \mathrm{O}$, and one might expect nucleation to occur more rapidly for $\mathrm{D}_{2} \mathrm{O}$ than $\mathrm{H}_{2} \mathrm{O}$. However, the converse was experimentally observed; therefore Burkett \& Davis suggest that the breaking of O-H (or O-D) bonds may play a significant role in the nucleation process. This is important for several reasons. First of all, these results provide experimental evidence to suggest that a stronger base does not necessarily cause faster nucleation. Secondly, the O-H (or O-D) bond breaking most likely is a significant factor in the nucleation process and must be considered in addition to the effects of structure-directing agents and alkali metal cations employed.

\section{CONTROL OF POROUS STRUCTURES THROUGH ORGANIC STRUCTURE-DIRECTING AGENTS}

The syntheses of high-silica zeolites appear to be the most prone to design via the use of structure-directing agents [this exploits the hydrophobic interactions between silica and the organic molecules and the ability to control the charge and shape of the organic (13)]. Lobo and co-workers (14) indicate that the molecular size (somewhat correlated to the total number of carbon and nitrogen atoms) of a structure-directing agent can strongly influence the number of different zeolites that can be synthesized using a particular organic molecule. (It has been shown experimentally 
that one organic can be responsible for the synthesis of more than one zeolite). Additionally, Zones noted that this trend is followed as the size of the organic molecule increases until only one zeolite structure is found for large structure-directing agents. Lobo et al recommend that larger organic molecules be investigated to synthesize new zeolite structures; however, the ratio of $\mathrm{C} / \mathrm{N}^{+}$must be kept somewhat within the previously mentioned limits in order to have the appropriate hydrophobicity/ hydrophilicity. The presence of two or more charged nitrogens can circumvent potential problems with hydrophobicity for large organic molecules (14).

\section{Examples of Structure-Direction}

The concepts of structure-direction discussed above are now illustrated using five examples. These examples demonstrate the effects of the geometry of the structure-directing agent on the geometry of the zeolite formed.

SSZ-26 is a zeolite with intersecting 10- and 12-ring pores (63). A propellane-based structure-directing agent, $I$, is used in the synthesis of SSZ-26 (64).

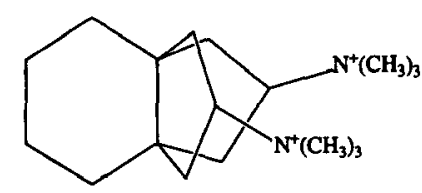

I

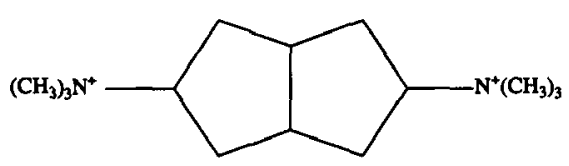

II

Zones \& Santilli (64) noted that organic cation II directed the synthesis of ZSM-12, a unidimensional zeolite. They speculated that the inclusion of another ring as in I would cause an intersecting pore system to form. Using the structure of SSZ-26 (65), chemical and thermogravimetric analyses indicate that one guest molecule is present in each channel intersection (14). Lobo et al (66) performed molecular force-field calculations on cation I inside the SSZ-26 pores and noted excellent agreement between the geometry of the organic cation and the geometry of the pore intersection. The conformation of minimum energy for I inside the channel intersections bears close resemblance to the conformation suggested by Zones \& Santilli (64). SSZ-26 thus appears to be the first zeolite where the pore geometry has been designed a priori (14). This example illustrates how the concepts of structure-direction can be used to synthesize new zeolites.

ZSM-18 has a unique structure in that it is the only aluminosilicate 


\section{HELMKAMP \& DAVIS}

containing 3-membered rings (67). An excellent fit exists between the zeolite cage and the organic structure-directing agent. Hong et al (68) used static and $\mathrm{CP}$ MAS ${ }^{13} \mathrm{C}$ NMR to determine that the triquaternary ammonium cation snugly fits inside the cage of ZSM-18. The size, rigidity, and especially the threefold axis of rotation of the organic molecule are factors favoring the formation of the ZSM-18 cage (14). Using this knowledge, Schmitt \& Kennedy (69) recently synthesized ZSM-18 using structure-directing agents III and IV.

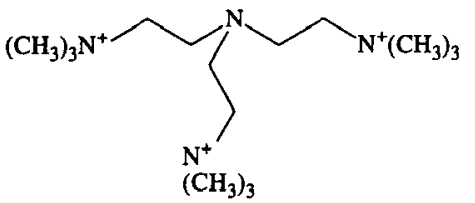

III

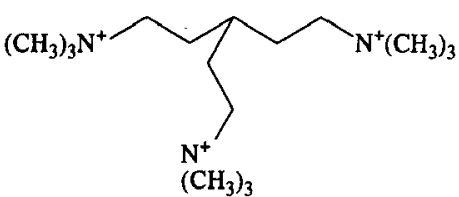

IV

Organic cations III and IV were chosen by using molecular modeling to help screen for potential replacements of the original ZSM-18 organic structure-directing agent. This is the first published result using molecular modeling to design a structure-directing agent.

Another example of the complementary relationship between the geometry of the organic molecule and the geometry of the zeolite void space is the occlusion of 18-crown-6 in the cages of EMC-2, the hexagonal polymorph of faujasite (14). 18-crown-6 is the only proven structuredirecting agent for the formation of EMC-2. It has been shown via X-ray diffraction (70) and solid-state NMR (71) results that 18-crown-6 is located inside the small cages of EMC-2 and roughly conforms to the cage geometry.

Arhancet \& Davis (72) provided the first example of exercising the purposeful control of long-range order in zeolite synthesis using structuredirecting agents. They were able to control the fractions of cubic and hexagonal polymorphs of faujasite present in intergrowth zeolites by specifying the concentrations of 15 -crown-5 and 18-crown-6 in the reaction mixture.

Lobo et al (73) have reported a second example of control of longrange order using structure-directing agents in the synthesis of the related materials CIT-1 and SSZ-33. CIT-1 and SSZ-33 are members of a family of polymorph structures (51). SSZ-33 is an intergrowth of polymorph A $(30 \%)$ and polymorph B (70\%), whereas CIT-1 is the pure polymorph B. By preparing synthesis gels in the presence of the structure-directing agents for SSZ-33 and CIT-1, the fractions of the two polymorphs in the resulting 
zeolites can be controlled in the range 70\% polymorph B (SSZ-33) to $100 \%$ polymorph B (CIT-1) (51). This example and the previous example from Arhancet \& Davis demonstrate the control of long-range order in zeolites using organic structure-directing agents.

\section{Heteroatoms and Structure-Direction by Organic Molecules}

The addition of small quantities of tetrahedral atoms besides silicon (Al, $\mathrm{Zn}, \mathrm{B}$, etc) to synthesis gels has dramatic effects on the zeolite structures formed when using identical structure-directing agents (14). Here we outline the changes in zeolite structures observed when aluminum, zinc, or boron is added to an otherwise pure-silica reaction mixture. Heteroatoms other than $\mathrm{B}, \mathrm{Zn}$, and $\mathrm{Al}$ have been incorporated in high-silica zeolite frameworks $(9,74)$, but they are not discussed here.

The syntheses of ZSM-12 and zeolite beta using TEA ${ }^{+}$as structuredirecting agent are used to illustrate the effect of adding aluminum to the synthesis gels while keeping other factors constant (see Table 2) (14). ZSM12 is formed when the ratio of $\mathrm{SiO}_{2}$ to $\mathrm{Al}_{2} \mathrm{O}_{3}$ is greater than 50 . As more aluminum is added and the ratio of $\mathrm{SiO}_{2}$ to $\mathrm{Al}_{2} \mathrm{O}_{3}$ becomes slightly less than 50 , zeolite beta is formed. If still more $\mathrm{Al}$ is included such that $\mathrm{SiO}_{2} /$ $\mathrm{Al}_{2} \mathrm{O}_{3} \sim 15, \mathrm{ZSM}-20$ results. When boron is used in place of aluminum, similar results occur. This trend is also observed for organics other than $\mathrm{TEA}^{+}$(see Table 2).

The structure-directing effects of organics that synthesize large-pore, pure-silica zeolites are closely related to the presence of heteroatoms in the synthesis gel (14). Trimethyl-2-adamantylammonium directs the structure of the unidimensional pore system in zeolite SSZ-24. However, the addition of boron to this synthesis results in the formation of SSZ-33, which has a multidimensional pore system (51). As indicated from the results shown in Table 2, some structure-directing agents that make SSZ31 (unidimensional pore system) with pure-silica reaction mixture also yield SSZ-33 when B is present.

If the organic structure-directing agent listed as the last entry of Table 2 is employed, different zeolites are obtained for pure-silica, aluminumcontaining, and boron-containing synthesis gels. When only aluminum is present, SSZ-37 is formed (65). SSZ-37 has a structure similar to that of NU-87 (75). Slightly smaller and larger organics do not direct the structure of SSZ-37. These results show how small changes in composition can lead to significant variations in the structures obtained.

As is true for aluminum and boron, adding zinc to a reaction mixture significantly alters the zeolite formed. Zinc is unique in that VPI- 8 is formed in all high-silica syntheses in which $\mathrm{Zn}$ is involved, regardless of the choice of structure-directing agent (14). Annen \& Davis $(76,77)$ first 
184 HELMKAMP \& DAVIS

Table 2 Effect of aluminum, boron and zinc on the structure of molecular sieves obtained using organic structure-directing agents ${ }^{\mathrm{a}}$ (adapted from Reference 14)

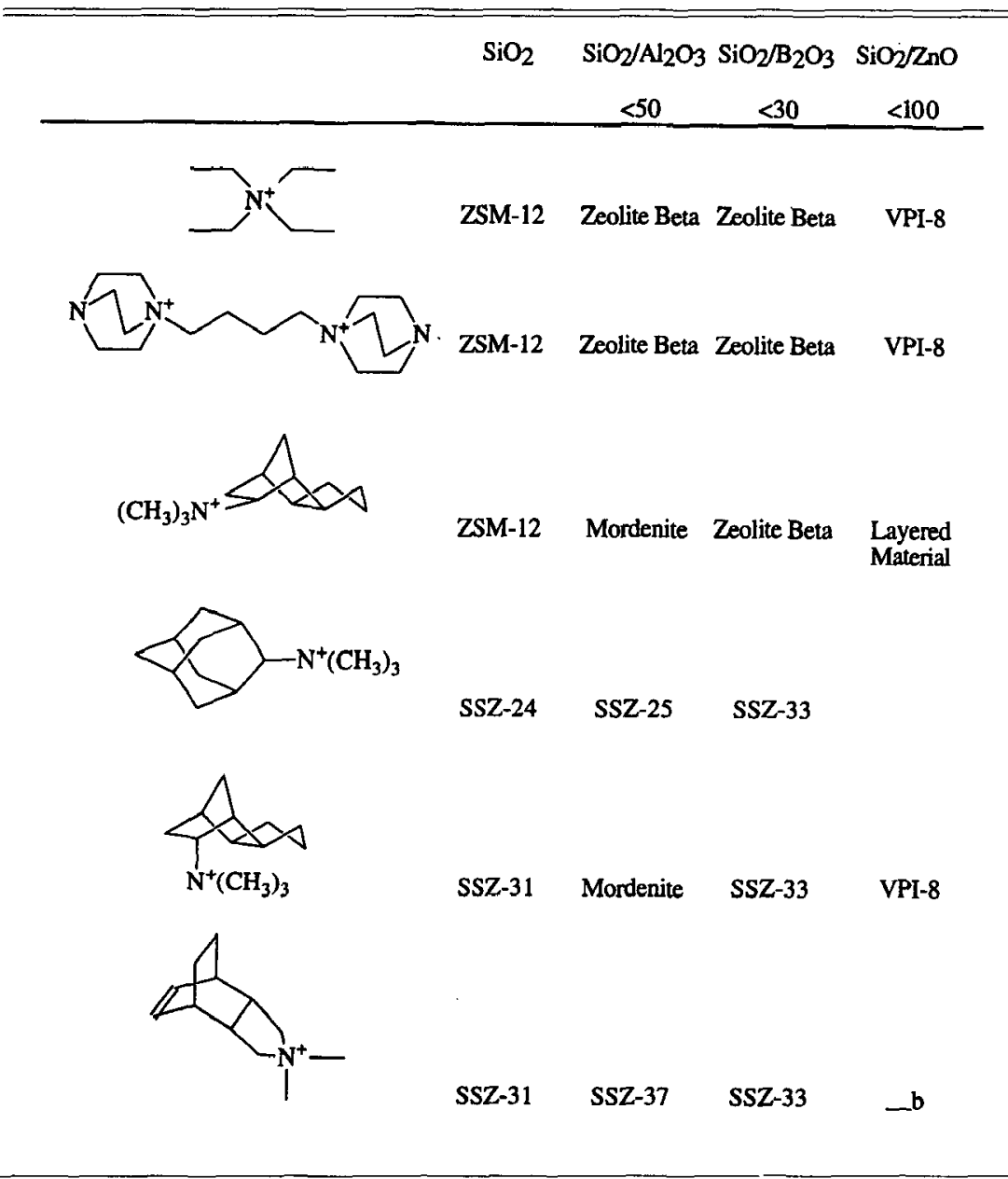

${ }^{a}$ From References 77, 79, 92-94; MA Camblor et al, submitted. Some of these results are from experiments in our laboratories and are not yet published.

No product formed after several weeks.

synthesized VPI-8 using $\mathrm{TEA}^{+}$as the structure-directing agent and zinc acetate as the source of zinc. Sorption and transmission electron microscopy (TEM) data show that VPI-8, is a one-dimensional large-pore molecular sieve. Because it is synthesized using a wide variety of organic guests, it is probable that a divalent zinc cation determines the structure 
of the resulting zeolite and that the organic structure-directing agent's primary role is to stabilize the void spaces of the pores (78). Zinc appears to inhibit the formation of other high-silica zeolites besides VPI-8.

Divalent and trivalent $T$ (tetrahedral) atoms in the synthesis gel should exert a strong influence on the formation of high-silica zeolites (14). First of all, substituting $\mathrm{Zn}, \mathrm{B}$, or $\mathrm{Al}$ for $\mathrm{Si}$ in the synthesis gel results in a negatively charged zeolite framework, which will coordinate more strongly with the inorganic cations, e.g. sodium or potassium, present in the reaction mixture. Secondly, the T-O bond lengths and especially the T-O-T angles should affect the formation of particular secondary building units, e.g. 4-rings (14). It is known that $\mathrm{Si}-\mathrm{O}-\mathrm{Al}$ and $\mathrm{Si}-\mathrm{O}-\mathrm{B}$ angles have more limited ranges of variation than $\mathrm{Si}-\mathrm{O}-\mathrm{Si}$ and that the optimum angles are smaller for the heteroatom angles than for $\mathrm{Si}-\mathrm{O}-\mathrm{Si}$. Thus the addition of framework heteroatoms is likely to cause structural variations.

It is interesting to examine the effects of heteroatoms by comparing the structures of zeolite beta and ZSM-12. The projections along the $a$ and $b$ axes of zeolite beta are identical to the projections along the 12-ring pores of ZSM-12. The disordered stacking of silicate layers is responsible for the structures of both zeolites $(79,80)$. There are also more 4-rings present in zeolite beta than in ZSM-12. The additional 4-rings in beta may result from smaller $\mathrm{Si}-\mathrm{O}-\mathrm{T}$ angles, which are promoted by the use of boron or aluminum (14).

\section{Specification of Framework Atoms by Structure-Directing Agents}

Recently, Li et al (81) have provided the first example of how to control the placement of framework atoms during a zeolite synthesis. Zeolites ZSM-11 and ZSM-5 were formed using the structure-directing agent $n$ trimethoxysilylpropyltri-n-butylammonium $\left(\mathrm{TBA}^{+}\right.$with a silicon alkoxide group covalently attached via a $\mathrm{Si}-\mathrm{C}$ bond on one of the alkyl groups as a substitute for a methyl group). Thermogravimetric analysis and ${ }^{13} \mathrm{C}$ and ${ }^{29} \mathrm{Si}$ NMR spectroscopy of ZSM-5 proved that the organosilicon structuredirecting agent resided intact at the channel intersections in the zeolite void space. It was also shown that the silicon atom in $n$-trimethoxysilylpropyltri- $n$-butylammonium was located in a framework position (81).

The consequences of the work of $\mathrm{Li}$ et al are rather broad. First of all, this work shows that there are new opportunities for making microporous materials using organic molecules with at least one silicon atom covalently bonded to a carbon atom in the structure-directing agent. Secondly, the covalent linking of atoms other than silicon to the organic molecules may make it feasible to arrange these heteroatoms in precise locations during 
the formation of new and previously known zeolites. Eventually it may be possible to distribute these atoms in one particular crystallographic position of a zeolite (81). Controlling atomic arrangements in this way would aid in developing completely uniform properties and in determining intrazeolite catalytic reaction pathways. As an example, the bridging $\mathrm{Al}-\mathrm{OH}-$ Si groups in ZSM-5 are heterogeneous in terms of acid strength. If all $\mathrm{Al}$ atoms in ZSM-5 could be distributed in identical T-sites, a material with homogeneous acid strength could be synthesized (81).

\section{ORDERED MESOPOROUS MATERIALS}

\section{From Microporous to Mesoporous Materials}

As mentioned previously, Burkett \& Davis (49) used the results of intermolecular ${ }^{1} \mathrm{H}-{ }^{29} \mathrm{Si}$ CP MAS NMR to propose a mechanism for the synthesis of zeolites with high $\mathrm{Si} / \mathrm{Al}$ ratios (see Figure 5). This proposed mechanism has several features common to other types of assembly processes, e.g. biological assemblies. These common elements are (a) the self-assembly process, which occurs spontaneously with no external mediating factors; $(b)$ the organization that involves structure-direction with many noncovalent interactions working together (multipositional molecular recognition events); and $(c)$ the process of self-assembly, which occurs such that the structural organization proceeds from molecules to composite structures of increasing size (82). In biological processes, organic materials larger than individual molecules usually act as templates (templating is a more precise form of structure-direction). Therefore one would expect organic molecular aggregates to function as structure-directing agents when synthesizing porous inorganic materials (82). Until the ordered mesoporous materials MCM-41 and MCM-48 were synthesized at Mobil, this had not been accomplished (83). MCM-41 is an (alumino) silicate possessing hexagonally arranged one-dimensional pores with diameters ranging from 15 to $100 \AA$. MCM-48 is an (alumino)silicate with a three-dimensional pore system and diameters of order $30 \AA$; its X-ray diffraction pattern has cubic symmetry with space group Ia3d (82-84). It is noteworthy that, unlike zeolites, the inorganic portions of mesoporous materials such as MCM-41 and MCM-48 are amorphous (alumino) silicates (26). This was shown by Raman, IR, and ${ }^{29} \mathrm{Si}$ NMR spectroscopies.

Consider the mixing of water with organic molecules of type $\left(\mathrm{CH}_{3}\right)_{3} \mathrm{~N}^{+}\left(\mathrm{CH}_{2}\right)_{x} \mathrm{CH}_{3}$. The molecules should remain isolated in solution if $x$ is small, e.g. $0 \leqslant x \leqslant 2$. When $x$ is larger, e.g. $x=15$ (hexadecyltrimethylammonium, $\mathrm{C}_{16} \mathrm{TMA}^{+}$), spontaneous self-assembly of the molecules can occur so that molecular aggregates are formed. The aggre- 
gates (micelles) contain hydrophilic polar groups that align at the waterorganic interface as well as hydrophobic hydrocarbon chains that collect in the center (82). For $\mathrm{C}_{16} \mathrm{TMABr}$ in water at ambient conditions, the critical micelle concentration is $0.03 \mathrm{wt} \%$ (85). To investigate if and how molecular aggregation affects synthesis, Davis et al (82) heated a synthesis gel with composition $0.15 \mathrm{~mol} \mathrm{C}_{16} \mathrm{TMA}_{2} \mathrm{O}: 1.0 \mathrm{~mol} \mathrm{SiO}_{2}: 50 \mathrm{~mol} \mathrm{H}_{2} \mathrm{O}$ at temperatures below and above $423 \mathrm{~K}$. At temperatures below $423 \mathrm{~K}$, MCM-41 was formed (pore diameter $\sim 30 \AA$ ), whereas temperatures above $423 \mathrm{~K}$ yielded the zeolite ZSM-48 (pore diameter $\sim 5 \AA$ ). ${ }^{13} \mathrm{C} \mathrm{CP}$ MAS NMR spectroscopy showed that the $\mathrm{C}_{16} \mathrm{TMA}^{+}$remains intact in $\mathrm{MCM}$ 41 and ZSM-48. These results are consistent with the idea that organic aggregation causes formation of mesoporous materials, whereas isolated organic molecules direct the structure of microporous zeolites (82).

\section{$M C M-41$ and $M C M-48$}

MCM-41 and MCM-48 are typically prepared via hydrothermal syntheses with $\mathrm{C}_{16} \mathrm{TMA}^{+}$and silica at temperatures below $423 \mathrm{~K}(82) . \mathrm{MCM}-41$ is usually formed with ratios of $\mathrm{C}_{16} \mathrm{TMA}^{+} / \mathrm{SiO}_{2} \leqslant 1(26,83,84)$. MCM-48 has been more difficult to synthesize than MCM-41. To prepare MCM48 , tetraethylorthosilicate (TEOS) is used as the silicon source and the ratio $\mathrm{C}_{16} \mathrm{TMA}^{+} / \mathrm{SiO}_{2}$ is typically $1.1-1.5$ (86).

Workers at Mobil suggested that MCM-41 can be obtained via one of two mechanisms (84). In the first, $\mathrm{C}_{16} \mathrm{TMA}^{+}$cations self-assemble into a hexagonal array of rod-like micelles in an aqueous phase (the $\mathrm{H}_{1}$ phase). After formation of the $\mathrm{H}_{1}$ phase, silicate species penetrate the region between the rod-like micelles and condense to make the final inorganicorganic material. In the second mechanism, the silicate species affects micelle formation and acts in concert to produce MCM-41. Chen et al (26, 87) studied the synthesis of MCM-41 with thermogravimetric analysis, $X$ ray powder diffraction, and ${ }^{29} \mathrm{Si}$ NMR spectroscopy of solid samples from throughout the MCM-41 synthesis. More importantly, Chen et al monitored the synthesis with in situ ${ }^{14} \mathrm{~N}$ NMR spectroscopy, which can detect the presence of the $\mathrm{H}_{1}$ phase. The $\mathrm{H}_{1}$ phase was not observed at any time during the synthesis (87), which indicates that a mechanism where the $\mathrm{H}_{1}$ phase forms is most likely not correct.

Chen et al $(26,87)$ suggested a mechanism for the formation of MCM41 as shown in Figure 8. Rod-like organic micelles initially form with random order. These micelles interact with silicate species through electrostatic interactions between surfactant cations and silicate anions to make micelles coated with silicate (a single layer of silica surrounding a rod-like micelle consists of approximately four silicon atoms per nitrogen atom; each surfactant head group has an approximate area of $50 \AA^{2}$ ) (88). 


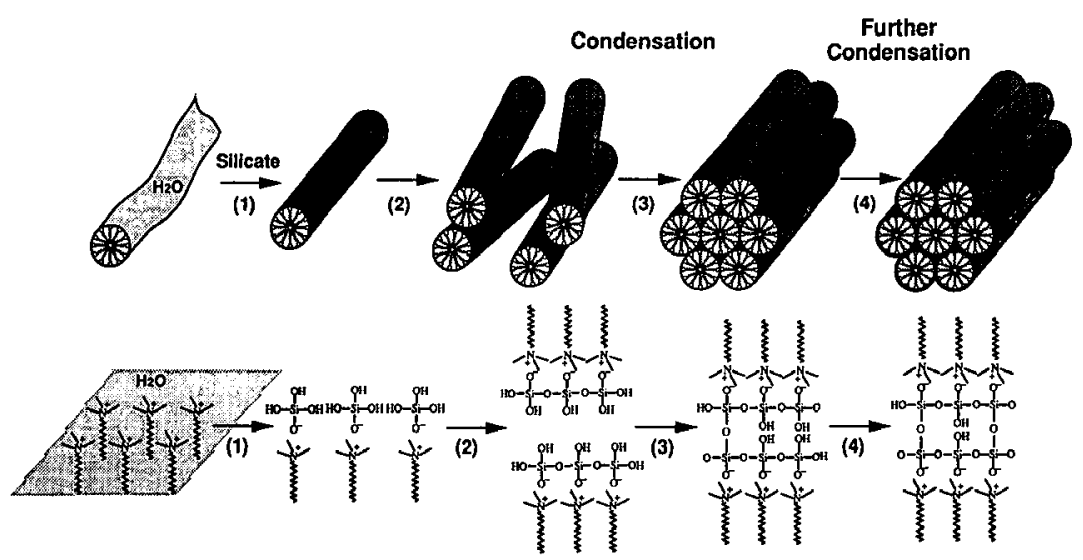

Figure 8 A proposed mechanism for the synthesis of MCM-41. (Adapted from 82.)

Condensation of the silicate species then orders the randomly ordered composite species to form a hexagonal array. Additional silicate condensation occurs while the species is in the hexagonal arrangement. The mechanism proposed by Chen et al suggests that MCM- 41 has a ratio of $\mathrm{Si} / \mathrm{N} \sim 4$ and a wall thickness of roughly $8 \AA$. Consistent with this mechanism, MCM-41 has been synthesized with $\mathrm{Si} / \mathrm{N}=3.5-4.5(26,84)$ and with wall thicknesses of $8-10 \AA(84,89)$. Beck et al (84) have also demonstrated that the pore diameter of MCM-41 can exceed the value resulting from the exclusive use of $\mathrm{C}_{16} \mathrm{TMA}^{+}$ions by adding hydrophobic organic molecules, e.g. 1,3,5-trimethylbenzene, to the reaction mixture. Using the synthesis mechanism proposed by Chen et al, one can rationalize the mechanism for this enlargement of pore diameter. The small organic molecules are adsorbed into the rod-like micelles and their diameters are then increased. This enlargement of the micelle size leads to the increase in the pore size of the resulting MCM-41 (82). Spegt et al (90) have documented swelling of $\mathrm{C}_{16} \mathrm{TMA}^{+}$micelles, lending further credence to the proposed mechanism. Absorption and swelling of the rod-like micelles may take place at any time before silica encapsulation (82).

\section{Synthesis of Microporous and Mesoporous Materials}

A comparison of synthesis routes for zeolites and ordered mesoporous materials reveals that many of the mechanistic steps are similar. Davis et al (82) provided a mechanism for the organic-mediated synthesis of ordered porous materials. This mechanism is discussed below.

Adding an organic molecule to an aqueous liquid-phase can result in the ordering of water in the vicinity of the organic. This "hydrophobic hydration" can take place around isolated molecules or organic aggregates 
that have self-assembled. Davis and co-workers $(13,49)$ proposed that molecules which do not order water will not be effective structure-directing agents. Under strongly basic conditions, hydroxyl anions enhance the depolymerization of silica when a non-monomeric silicon source is used, e.g. fumed silica, amorphous silica. The hydrated organic entities have coulombic interactions with the soluble silicate species, and the quaternary ammonium cations promote the condensation of the silicate species. Therefore, the geometry of the organic component influences the geometry of the inorganic species via multipositional molecular-level interactions (van der Waals and coulombic; van der Waals interactions become important after the silicate species condense to make hydrophobic domains) (49). The inorganic-organic composites then merge to create materials with longer-range order. The assembly process has enthalpic and entropic driving forces; the energetically favorable inorganic-organic interactions and the release of ordered water molecules from around the organic species to bulk water in solution favor synthesis of the porous structures (82). The inorganic portion can form crystalline phases in microporous materials, and the properties of the inorganic component play a critical role in determining the final structures formed. If self-assembled organic aggregates behave as structure-directing agents, many silicate anions were needed to balance the charge of the organic cations. As an example, the product ratio $\mathrm{Si} / \mathrm{N}$ in $\mathrm{MCM}-41$ is approximately 3.5-4.5. This low ratio is likely the reason that materials such as MCM-41 and MCM-48 do not have crystalline walls because the amount of silicon required for charge compensation of the organic cation is too large to permit formation of a crystalline oxide (82). Zeolites typically have $\mathrm{Si} / \mathrm{N}$ ratios of 7 (beta)-23 (ZSM-5). Finally, the syntheses of ordered mesoporous materials and zeolites can be viewed as examples of a unified strategy of self-assembly whereby structure-direction occurs through a number of noncovalent interactions between inorganic and organic components. These interactions work together to establish order of increasing length scales throughout the synthesis (82). It should also be noted that the inorganicorganic composites are formed by kinetically controlled processes in contrast to mesoscopic organic phases produced in binary water-organic systems (82). These concepts are also important in biological assemblies and in the inorganic-organic composites of biomineralization of pure organic phases (91).

\section{SUMMARY AND FUTURE DIRECTIONS}

The mechanisms by which porous silicates are formed still remain unknown. Here we have provided an overview of the types of information that are 
currently available that enable one to begin to rationalize the assembly processes. Using existing data, partial designs of synthetic strategies are now appearing, e.g. SSZ-26, ZSM-18. Ultimately, the hope is that completely designed syntheses can be accomplished. By comparing and contrasting the assembly processes of porous silicate synthesis to those of other self-assembly processes, e.g. biomineralization, the elucidation of universal rules of construction for inorganic-organic composites may be possible. At this time, we believe that the most critical issues in the area of porous silicate synthesis are investigation of the nucleation process and determination of the precise structures of the nuclei. If these issues can be resolved, we believe that porous silicate synthesis by design will become a reality.

\section{ACKNOWLEDGMENTS}

The authors acknowledge helpful discussions with Stacey Zones of Chevron Research and Technology Company, John Higgins of Mobil Research and Development Corporation, Kenneth Pitzer of the University of California at Berkeley, and Raul Lobo, Sandra Burkett, Chris Dartt, CongYan Chen, Hubert Koller, George Gavalas, and Zhen-Gang Wang, all from the California Institute of Technology.

Any Annual Review chapter, as well as any article cited in an Annual Review chapter, may be purchased from the Annual Reviews Preprints and Reprints service. 1-800-347-8007; 415-259-5017; email: arpr@class.org

\section{Literature Cited}

1. Cronstedt AF. 1756. Svenska Vetenskaps Akademiens Handlingar, Stockholm 17: 120-23

2. Schlenker JL, Kuhl GH. 1993. Ninth Int. Zeolite Conference, Montreal, ed. R von Ballmoos, JB Higgins, MM Treacy, pp. 3-9. Boston: Butterworth-Heinemann

3. Davis ME. 1991. Ind. Eng. Chem. Res. 30: 1675-83

4. Löewenstein W. 1954. Am. Mineral. 39: 92-96

5. Milton RM. 1959. U.S. Patent Nos. $2,882,243 ; 2,882,244$

6. Milton RM. 1968. Soc. Chem. Ind.pp. 199-203

7. Breck DW. 1974. Zeolite Molecular Sieves, New York: Wiley \& Sons. 771 pp.

8. Newsam JM. 1986. Science 231: 109399

9. Newsam JM. 1992. In Solid State Chemistry: Compounds, ed. AK Cheetham, $\mathrm{P}$ Day, pp. 234-80. New York: Oxford Univ. Press
10. Smith JV. 1988. Chem. Rev. 88: 149-82

11. Davis ME. 1993. Acc. Chem. Res. 26: 111-15

12. Gies H. 1991. In Inclusion Compounds, ed. JL Atwood, JED Davies, DD MacNicol, pp. 1-36. Oxford: Oxford Univ. Press

13. Davis ME, Lobo RF. 1992. Chem. Mater. 4: 756-68

14. Lobo RF, Zones SI, Davis ME. 1994. In Inclusion Chemistry with Zeolites. Nanoscale Materials by Design, ed. N Herron, D Corbin. In press

15. Burkett SL, Davis ME. 1994. In Comprehensive Supramolecular Chemistry, ed. JM Lehn. In press

16. Higgins JB. 1994. In Reviews in Mineralogy: Silica Polymorphs, ed. PH Ribbe. Vol. 29. Washington DC: Mineral. Soc. Am. In press

17. Flanigen EM, Bennett JM, Grose RW, Cohen JP, Patton RL, et al. 1979. $N a$ ture 271: $512-16$

18. Meier WM, Olson DH. 1992. Atlas of 
Zeolite Structure Types. London: Butterworth-Heinemann. $200 \mathrm{pp}$.

19. Liebau F. 1983. Zeolites 3: 191-93

20. Liebau F, Gies H, Gunawardane RP, Marler B. 1986. Zeolites 6: 373-77

21. Davis ME. 1994. CHEMTECH 24: 2226

22. Petrovic I, Navrotsky A, Davis ME, Zones SI. 1993. Chem. Mater. 5: 180513

23. Maniar PD, Navrotsky A, Rabinovich EM, Ying JY, Benziger JB. 1990. J. NonCryst. Solids 124: 101-11

24. Ying JY, Benziger JB, Navrotsky A. 1993. J. Am. Ceram. Soc. 76: 2571-82

25. Navrotsky A, Petrovic I, Hu Y, Chen CY, Davis ME. 1994. Microporous Mater. In press

26. Chen CY, Li HX, Davis ME. 1993. Microporous Mater. 2: 17-26

27. Geisinger KL, Gibbs GV, Navrotsky A. 1985. Phys. Chem. Minerals 11: 266-93

28. Johnson GK, Tasker IR, Howell DA. 1987. J. Chem. Thermodyn. 19: 617-32

29. Robie RA, Hemingway BS, Fisher JR. 1978. Thermodynamic Properties of Minerals and Related Substances at $298.15 K$ and 1 Bar (105 Pascals) Pressure and at Higher Temperatures. Washington DC: US Gov, Printing Office, $456 \mathrm{pp}$.

30. Richet $\mathbf{P}$, Bottinga $Y$, Denielou L, Petitet JP, Tequi C. 1982. Geochim. Cosmochim. Acta 46: 2639-58

31. Akaogi M, Navrotsky A. 1984. Phys. Earth Planet. Inter. 36: 124-34

32. Patarin J, Kessler H, Soulard M, Guth JL. 1989. Am. Chem. Soc. Symp. Ser. 398: 221-32

33. Johnson DA, Martin JF. 1973. J. Chem. Soc. Dalton Trans. 15: 1585-90

34. Lewis GN, Randall M, eds. 1961. Thermodynamics, revis. KS Pitzer, L Brewer, 2nd ed. New York: McGrawHill. 723 pp.

35. Tanford C. 1980. The Hydrophobic Effect: Formation of Micelles and Biological Membranes. New York: Wiley. $233 \mathrm{pp}$.

36. Frank HS, Evans MW. 1945. J. Chem. Phys. 13: 507-32

37. Lindenbaum S, Boyd GE. 1964. J. Phys. Chem. 68: 911-17

38. Krishnan CV, Friedman HL. 1969. J. Phys. Chem. 73: 3934-40

39. Frank HS, Wen WY. 1957. Discuss. Faraday Soc. 24: 133-40

40. Burkett SL, Davis ME. 1994. J. Chem. Mater. In press

41. Wen WY, Saito S. 1964. J. Phys. Chem. 68: 2639-44

42. Wen WY, Saito S. 1965. J. Phys. Chem. 69: 3569-74

43. Agar JN. 1963. In Advances in Electro- chemistry and Electrochemical Engineering, ed. P Delahay, pp. 31-121. New York: Wiley

44. Price CD. 1961. PhD thesis. Cambridge Univ.

45. van Santen RA, Ooms G, den Ouden CJJ, van Beest BW, Post MFM. 1989. Am. Chem. Soc. Symp. Ser. 398: 617-33

46. Shimizu A, Taniguchi Y. 1990. Bull. Chem. Soc. Jpn. 63: 1572-77

47. Shimizu A, Taniguchi Y. 1990. Bull. Chem. Soc. Jpn. 63: 3255-59

48. Gies H, Marler B. 1992. Zeolites 12: 4249

49. Burkett SL, Davis ME. 1994. J. Phys. Chem. 98: 4647-53

50. Lobo RF, Davis ME. 1993. U.S. Patent. Application pending

51. Lobo RF, Pan M, Chan I, Li HX, Medrud RC, et al. 1993. Science 262: 154346

52. Treacy MMJ, Newsam JM. 1988. Nature 332: 249-51

53. Higgins JB, Lapierre RB, Schlenker JL, Rohrman AC, Wood JD, et al. 1988. Zeolites 8: 446-52

54. Liebau F, ed. 1985. Structural Chemistry of Silicates. Berlin: Springer-Verlag. 347 pp.

55. Griffen DT, ed. 1992. Silicate Crystal Chemistry. New York: Oxford Univ. Press. 442 pp.

56. Harris TV, Zones SI. 1994. Stud. Surf. Sci. Catal. 94: 29-36

57. Goepper M, Li HX, Davis ME. 1992. J. Chem. Soc. Chem. Commun. 22: 166566

58. Dove PM, Crerar DA. 1990. Geochim. Cosmochim. Acta 54: 955-69

59. Brady P, Walther JV. 1990. Chem. Geol. 82: 253-64

60. Zones SI. 1994. Microporous Mater. 2: 281-87

61. Brown ID. 1981. In Structure and Bonding in Crystals, ed. M O'Keeffe, A Navrotsky, pp. 1-30. New York: Academic

62. Dutta PK, Purl M, Bowers C. 1989. Am. Chem. Soc. Symp. Ser. 398: 98-109

63. Zones SI, Olmstead MM, Santilli DS. 1992. J. Am. Chem. Soc. 114: 4195-201

64. Zones SI, Santilli DS. 1993. In Proc. Ninth Int. Zeolite Conf., Montreal ed. R von Ballmoos, JB Higgins, MMJ Treacy, pp. 171-79. Boston: Butterworth-Heinemann

65. Nakagawa Y. 1993. U.S. Patent No. $5,254,514$

66. Lobo RF, Pan M, Chan I, Zones SI, Crozier PA, Davis ME. 1994. J. Phys. Chem. 98: 12040-52

67. Lawton SL, Rohrbaugh WJ. 1990. Science 247: 1319-22 


\section{HELMKAMP \& DAVIS}

68. Hong SB, Cho HM, Davis ME. 1993. J. Phys. Chem. 97: 1622-28

69. Schmitt KD, Kennedy GJ. 1994. Zeolites 14: 635-42

70. Baerlocher C, McCusker LB, Chiappetta R. 1994. Microporous Mater. 2: 269-80

71. Burkett SL, Davis ME. 1993. Microporous Mater. 1: 265-82

72. Arhancet JP, Davis ME. 1991. Chem. Mater. 3: 567-69

73. Lobo RF, Zones SI, Davis ME. 1994. Stud. Surf. Sci. Catal. 84: 461-68

74. Szostak R. 1992. Handbook of Molecular Sieves. New York: Van Nostrand Reinhold. $584 \mathrm{pp}$.

75. Nakagawa Y. 1994. Stud. Surf. Sci. Catal. 84: 323-30

76. Annen MJ. 1992. Synthesis and characterization of novel molecular sieves containing three-membered rings (zincosilicate gels). $\mathrm{PhD}$ thesis. Virginia Polytech. Inst. 145 pp.

77. Annen MJ, Davis ME. 1993. Microporous Mater. 1: 57-65

78. Deleted in proof

79. Fyfe CA, Gies H, Kokotailo GT, Marler B, Cox DE. 1990. J. Phys. Chem. 94: 3718-21

80. Newsam JM, Treacy MMJ, Koetsier WT, de Gruyter CB. 1988. Proc. R. Soc. London Ser. A 420: 375-405

81. Li HX, Camblor MA, Davis ME. 1994. Microporous Mater. 3: 117-21

82. Davis ME, Chen CY, Burkett SL, Lobo RF. 1994. In 1994 Mater. Res. Soc. Spring Meeting: Better Ceramics
Through Chemistry VI, San Francisco. 346: 831. Pittsburgh, PA: Mater. Res. Soc.

83. Kresge CT, Leonowicz ME, Roth WJ, Vartuli JC, Beck JS. 1992. Nature 359: 710-12

84. Beck JS, Vartuli MC, Roth WJ, Leonowicz ME, Kresge CT, et al. 1992. J. Am. Chem. Soc. 114: 10834-43

85. Lindblom G, Lindman B, Mandell L. 1973. J. Colloid Interface Sci. 42: 400-9

86. Kresge CT, Leonowicz ME, Roth WJ, Schmitt KD, Vartuli JC. 1993. U.S. Patent No. 5,198,203

87. Chen CY, Burkett SL, Li HX, Davis ME. 1993. Microporous Mater. 2: 27-34

88. Fontell K. 1990. Colloid Polymer Sci. 268: 264-85

89. Monnier A, Schuth F, Huo Q, Kumar D, Margolese D, et al. 1993. Science 261: 1299-303

90. Spegt PPA, Skoulios AE, Luzzati V. 1961. Acta Crystallogr. 14: 866-72

91. Mann S, Archibald DD, Didymus JM, Douglas T, Heywood BR, et al. 1993. Science 261: 1286-92

92. Nakagawa Y, Zones SI. 1992. In Synthesis of Microporous Materials, ed. ML Occelli, H Robson, pp. 222-39. New York: Van Nostrand Reinhold

93. Zones SI, Nakagawa Y. 1994. Microporous Mater. 2: 543-55

94. Kumar R, Reddy KR, Raj A, Ratnasamy P. 1993. In Proc. Ninth Int. Zeolite Conf. Montreal, ed. R von Ballmoos, JB Higgins, MM Treacy, pp. 189-96. Boston: Butterworth-Heinemann 


\section{CONTENTS}

Electronic Structure Theory in the New Age of Computational Materials Science, Arthur J. Freeman

Density Functional Theory as a Major ToOl in Computational Materials Science, Arthur J. Freeman, Erich Wimmer

Molecular Orbital Models of Silica, L. L. Hench, J. K. West 37

Modeling the DeVelopment and Relaxation of STRESSES IN Films, M. D. Thouless

LASER-BEAM InTERACTION WITH DEFECTS ON SEMICONDUCTOR SuRfaCES: An Approach to Production of Defect-Free Surfaces, Noriaki Itoh, Jyun'ichi Kanasaki, Akiko Okano, Yasuo Nakai

Magnetism and Giant Magneto-Transport Properties in Granular Solids, C. L. Chien

Synthesis of Porous Silicates, M. M. Helmkamp, M. E. Davis 161

The Nature of Grain Boundaries in the High $\mathrm{T}_{\mathrm{C}}$ SUPERCONDUCTORS, S. E. Babcock, J. L. Vargas

$\triangleright$ Laser-Induced Phase Transitions in Semiconductors, Y. Siegal, E. N. Glezer, L. Huang, E. Mazur

Phase Transitions in III-V Compounds to Megabar Pressures, Arthur L. Ruoff, Ting Li

Ferroelectric Thin Films for Photonics: Properties and Applications, D. Dimos

The Ultimate Strength and Stiffness of Polymers, Buckley Crist

Interfaces Between InCOMPatible Polymers, Manfred Stamm, Dirk Wolfram Schubert

Giant Magnetoresistance, $S$. S. P. Parkin

$\triangleright$ Epitaxy of Dissimilar Materials, $C$. J. Palmstrom 
viii CONTENTS (continued)

$\triangleright \mathrm{GeSi} / \mathrm{Si}$ Nanostructures, E. A. Fitzgerald

Spin Polarized Photoemission, P. D. Johnson

$\triangleright$ Fullerenes and Fullerene-Derived Solids as Electronic Materials, M. S. Dresselhaus, G. Dresselhaus

$\triangleright$ Metalorganic Chemical Vapor Deposition of Oxide Thin Films For EleCtronic and Optical Applications, Bruce W. Wessels

$\triangleright$ Low-Temperature Grown III-V Materials, $M . R$. Melloch, J. M. Woodall, E. S. Harmon, N. Otsuka, Fred H. Pollak, D. D. Nolte, R. M. Feenstra, M. A. Lutz

$\triangleright$ Luminescence as a Diagnostic of Wide-Gap II-VI Compound Semiconductor Materials, $B$. J. Skromme

$\triangleright$ Metal-Oxide Heterostructures, $R$. Ramesh, $V$. G. Keramidas

$\triangleright$ High-Temperature Superconducting Multilayers and Heterostructures Grown By Atomic Layer-By-LAyer Molecular Beam Epitaxy, J. N. Eckstein, I. Bozovic

$\triangleright$ Wide Bandgap II-VI Heterostructures for Blue/Green Optical Sources: Key Materials Issues, Leslie A. Kolodziejski, Robert L. Gunshor, Arto V. Nurmikko

INDEXES

Subject Index

Cumulative Index of Contributing Authors, Volumes 21-25 766

Cumulative Index of Chapter Titles, Volumes 21-25

768

$\triangleright$ Keynote Topic: Electronic Materials 